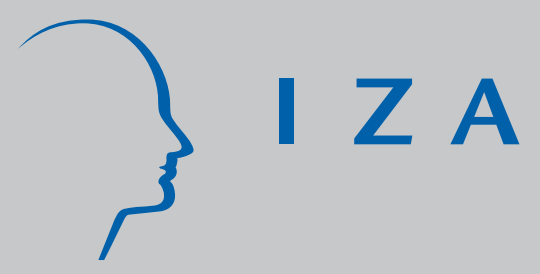

IZA DP No. 2953

Modeling the Signaling Value of the GED with an Application to an Exogenous Passing Standard Increase in Texas

Magnus Lofstrom

J ohn Tyler

J uly 2007 


\title{
Modeling the Signaling Value of the GED with an Application to an Exogenous Passing Standard Increase in Texas
}

\author{
Magnus Lofstrom \\ University of Texas at Dallas \\ and IZA \\ John Tyler \\ Brown University and NBER
}
Discussion Paper No. 2953
July 2007

IZA

P.O. Box 7240

53072 Bonn

Germany

Phone: +49-228-3894-0

Fax: +49-228-3894-180

E-mail: iza@iza.org

\begin{abstract}
Any opinions expressed here are those of the author(s) and not those of the institute. Research disseminated by IZA may include views on policy, but the institute itself takes no institutional policy positions.

The Institute for the Study of Labor (IZA) in Bonn is a local and virtual international research center and a place of communication between science, politics and business. IZA is an independent nonprofit company supported by Deutsche Post World Net. The center is associated with the University of Bonn and offers a stimulating research environment through its research networks, research support, and visitors and doctoral programs. IZA engages in (i) original and internationally competitive research in all fields of labor economics, (ii) development of policy concepts, and (iii) dissemination of research results and concepts to the interested public.
\end{abstract}

IZA Discussion Papers often represent preliminary work and are circulated to encourage discussion. Citation of such a paper should account for its provisional character. A revised version may be available directly from the author. 


\section{ABSTRACT}

\section{Modeling the Signaling Value of the GED with an Application to an Exogenous Passing Standard Increase in Texas}

In this paper we develop a simple model of the signaling value of the GED credential. The model illustrates necessary assumptions for a difference-in-difference estimator, which uses a change in the GED passing standard, to yield unbiased estimates of the signaling value of the GED for marginal passers. We apply the model to the national 1997 passing standard increase which affected GED test takers in Texas. We utilize unique data from the Texas Schools Micro Data Panel (TSMP) which contain demographic and GED test score information from the Texas Education Agency linked to pre- and post-test taking Unemployment Insurance quarterly wage records from the Texas Workforce Commission. Comparing Texas dropouts who acquired a GED before the passing standard was raised in 1997 to dropouts with the same test scores who failed the GED exams after the passing standard hike, we find no evidence of a positive GED signaling effect on earnings. However, we find some evidence which suggest that our finding may be due to the low GED passing threshold that existed in Texas for an extended period.

JEL Classification: $\quad$ 12, J31

Keywords: GED, signaling, returns to education, natural experiment

Corresponding author:

Magnus Lofstrom

University of Texas at Dallas

School of Economic, Political, and Policy Sciences

P.O. Box 830688

GR 31

Richardson, TX 75083-0688

USA

E-mail: lofstrom@utdallas.edu

\footnotetext{
* We would like to thank Jean Kimmel, Jeffrey Kling and Richard Murnane, seminar participants at Concordia U, Federal Reserve Bank of St. Louis, University of Texas at Arlington, UT Dallas and participants at the 2004 SOLE annual meeting in San Antonio and 2004 WEA annual meeting in Vancouver, Canada for helpful comments.
} 


\section{Introduction}

The General Educational Development certificate (GED) is an exam-based credential awarded to about 500,000 high school dropouts in the U.S. each year, representing almost 15 percent of all high school diplomas, or credentials, issued. Lacking a high school diploma to certify successful completion of their secondary schooling experience, the GED is the first, and often only, credential high school dropouts receive. One reason many dropouts seek a GED certificate is a belief that it will lead to greater labor market success. Several studies over the last decade have attempted to determine whether this is indeed the case, with the research questions breaking along two lines: How do GED holders compare to regular high school graduates? And, how do GED holders compare to other, uncredentialed high school dropouts?

Most observers agree that the first question has been answered rather convincingly by Cameron and Heckman (1993). They find that GED holders fare consistently worse than regular high school graduates on any number of labor market outcomes. These results were notable, but hardly surprising given the differences in human capital opportunities between students who drop out and pursue a GED and students who stay in school until graduation. The most recent data on GED preparation time indicates that the median study time was only about 30 hours (Baldwin 1990), substantially less than the 410 hours spent on a high school's core curriculum in a typical school year and probably insufficient time for meaningful human capital accumulation.

An answer to the second question - how do GED holders fare relative to uncredentialed dropouts - is somewhat more contentious, Again, the relatively low levels of time spent preparing for the GED suggest to many that pursuit of the GED credential 
could hardly have a substantial human capital component. This, of course, leaves open to question the potential of the GED as a labor market signal, a proposition studied by Tyler, Murnane, and Willett (2000). Using interstate variation in the standard required to pass the GED exams and acquire the credential, they find GED "signaling effects" of between 10 to 19 percent on annual earnings.

Similar to Tyler, Murnane, and Willett, the research strategy in this paper also utilizes different passing standards faced by different groups of dropouts. We use a 1997 change in Texas in the GED passing standards to identify the signaling value of the GED on the labor market outcomes of dropouts in that state. We argue that the changes in Texas give rise to a natural experiment that can be exploited to identify the labor market signaling effects of the GED on earnings, reducing endogeneity due to correlation between the outcome of passing/not passing and unobserved individual heterogeneity that may bias Ordinary Least Squares (OLS) estimates.

The American Council on Education (ACE) administers the nation's GED testing program and sets the minimum requirements for obtaining the credential. States can, and regularly have, set state level passing standards above the ACE-mandated minimum. Prior to 1997, Texas was one of the few states whose passing standard was at the ACE minimum level. As a result, Texas had one of the country's least stringent GED passing standards. In 1997 the ACE mandated a nationwide increase in the minimum passing standard, a change that was arguably exogenous to Texas. Given these changes and data on individuals containing GED test scores, we can identify an "affected score group" of GED candidates whose eventual GED status is "affected" by the change in the passing standard. Members of the "affected score group" who took the GED exams before 1997 
had high enough scores to be awarded a GED, while dropouts in this group with the exact same scores, but who attempted the GED exams after the passing standard hike in January 1, 1997, would have scores below the passing threshold and hence would not be awarded the credential. Since only the passing threshold and not the GED exams themselves changed in January of 1997, and since the raising of the threshold was by the ACE in Washington, DC, rather than by Texas policy makers, this occurrence provides us with a clearly defined natural experiment that can be exploited to estimate the impact of the GED on labor market outcomes. Because we are comparing individuals who have the same test scores but differ in GED status according to the year in which they attempted the exams, a strict interpretation of our results is that they estimate the labor market signaling value of the GED.

\section{The GED and the Earnings of Dropouts}

The GED is an exam-based credential that is awarded based on the scores on five different exams: math, science, social studies, reading, and writing. All of the test items in the GED exam battery are multiple choice except for a section in the writing exam that requires GED candidates to write an essay. ${ }^{1}$ The total exam battery takes about seven and one-half hours, and GED examinees who fail to score sufficiently high to "pass" may, under certain circumstances retake any or all of the exams in the battery. The growth in this education credential has coincided with substantial research efforts over the last decade.

\footnotetext{
${ }^{1}$ GED candidates are not required to take all of the five exams in one sitting.
} 
Cameron and Heckman (1993) first drew attention to the GED credential and the fact that male GED-holders are not the labor market equivalents of regular high school graduates. Studies that followed their research focused on the question of how GED holders compare to dropouts in the labor market who lack the credential. That is, once the drop out decision has been made, does the GED buy you anything in the labor market? While the answer has been somewhat mixed, two recent studies-each of which uses a different data set and a different empirical strategy_offer evidence that lower skilled GED holders have higher earnings than comparably low-skilled dropouts who lack a GED (Murnane, Willett, and Tyler 2000; Tyler, Murnane, and Willett 2000). In addition, Murnane, Willett, and Tyler (2000) offer a discussion of how these more recent results can be reconciled with the earlier Cameron and Heckman findings. Later work by Heckman, Hsse, and Rubinstein (2000) finds that failing to control for time-invariant heterogeneity between low-skilled credentialed and uncredentialed dropouts may lend an upward bias to estimates of a GED treatment effect. However, estimates from both individual fixed effects models and a regression discontinuity design (Tyler 2004) provide additional evidence that acquisition of a GED can improve the earnings of dropouts. To summarize recent research, it is fair to say that while there is still some ambiguity about the causal effect of the GED on labor market outcomes, the recent research tends to support a view that the credential has beneficial effects for the least skilled dropouts.

The data in this paper contain information on the quarterly earnings of dropouts who attempt to acquire a GED credential. For those dropouts who pass the GED exams, there are several mechanisms through which acquisition of a GED could impact the 
quarterly earnings of dropouts. First, employers may use the GED as a signal of productive attributes in a pool of dropouts, choosing to hire GED holders over uncredentialed dropouts (Spence 1973). If this were the case, then we would expect to see higher employment rates among the GED holders. Also, conditional on being employed, employers may use the GED as a positive signal of productivity and hence offering and assigning higher wages and/or more hours of work. In all cases we would expect the earnings of GED holders to be higher than the earnings of uncredentialed dropouts.

Second, there could be a human capital impact on the wages. Dropouts obtain a GED by gaining a passing score on a five-test examination battery that takes about seven and one-half hours to complete. To the extent that school dropouts have to work and prepare to increase their cognitive skills in order to achieve a passing score on the GED exams, then the opportunity to be awarded the credential could lead to human capital gains. As mentioned earlier, the only available data on time spent studying for the GED indicates a median study time of about 30 hours, too little for human capital accumulation. However, the Baldwin (1990) study generating those estimates did not distinguish between successful and unsuccessful GED candidates, nor did it include the time that dropouts might have spent in Adult Basic Education, English Second Language, or pre-GED classes in the estimate. As a result, the time spent by successful candidates could be longer than the study estimate. It may also be the case that today's dropouts, especially foreign schooled immigrants, may spend more time in GED preparation than the survey respondents in the 1990 study. Thus, the extent to which the GED program fosters human capital accumulation is still arguably an empirical question. 
Third, GED holders can use the credential to gain access to, and funding for, postsecondary education. Most degree granting postsecondary education programs require applicants to possess a high school diploma or a GED. Also, Pell grants and guaranteed federal student loans for postsecondary education require applicants to demonstrate an "ability to benefit" from the funding. Dropout applicants for these federal monies can satisfy this requirement if they possess a GED. It should be pointed out that previous research indicates that relatively few GED holders obtain substantial amounts of post-secondary education. Murnane, Willett and Boudett (1997) report that only 12 percent receive at least 1 year of college schooling and 3 percent obtained an Associate degree.

As with any program evaluation in which the selection process cannot be adequately modeled, we are concerned about the role of individual unobserved heterogeneity. We address this problem by exploiting the natural experiment that resulted when the passing standard required to obtain a GED in Texas was raised for everyone who took the GED exams on or after January 1, 1997. In simplest terms, we will compare the labor market outcomes of GED candidates who have the same GED test scores, but who vary in GED status depending on whether they tested in the years before the hike in the passing standard or in the years after the hike. We will also account for changes in overall labor market conditions for low skilled workers by subtracting out changes in earnings experienced by GED test takers whose scores were not affected by the passing standard change.

Although the GED credential may have a human capital effect on earnings, our approach assesses the signaling value of the GED. Hence, we will present a simple 
signaling model which illustrates the necessary assumptions for our approach to be valid. To implement the above strategy we define three score groups; a group whose scores were too low to pass under either passing standard (All Fail), a group whose score were sufficiently high that they would pass under either passing standard (All Pass) and a group whose scores were in the range such that the outcome was affected by the passing standard (Affected Score Group). Specifically, a GED candidate is defined to be in the affected score group if his scores are such that either the minimum score on the five GED exams is at least 40 or the average the five scores is at least 45 , while simultaneously the candidate does not have a minimum score of 40 and an average of at least 45 . We identify individuals in the three score groups both before and after the passing standard hike, yielding six distinct groups. The defined groups are:

1. The group of individuals who tested under the old passing standard and whose scores were too low to pass under either standard. This group attempted the GED in 1995 (All Fail -Pre).

2. The group of individuals who tested under the new passing standard, but whose scores were too low to pass under either standard, including the old standard. This group attempted the GED in 1997 (All Fail-Post).

3. The treatment group of individuals who barely passed the GED exams before the change in the passing standard. This group attempted the GED in 1995 (ASG-Pre).

4. The comparison, or control, group of individuals with the same GED test scores as the treatment group, but who lack a GED because they tested 
under the new, higher standard. This group attempted the GED in 1997 (ASG-Post).

5. The group of individuals who tested under the old regime, but whose scores were high enough so that they would have passed under the new standard. This group attempted the GED in 1995 (All Pass-Pre).

6. The group of individuals who tested under the new regime and whose scores would have been passing under either passing standard. This group attempted the GED in 1997 (All Pass-Post).

Next, we develop a simple signaling model using the above outcome groups to assess the signaling value of the GED.

\section{A Simple Signaling Model}

We utilize the well-known signaling model based on the work by Spence (1973) and Stiglitz (1975). In this model workers choose education not to increase their productivity, as in the human capital model, but to signal to employers their productivity.

The general model assumes $k$ kinds of workers with unobserved ability $\theta_{j}$, $j=1,2, . . \mathrm{k}$ and $k$-1 educational levels, $E D$. Let $\theta_{1}>\theta_{2}>\theta_{3}>\ldots>\theta_{k}$, i.e. $\theta_{1}$ is more "able", or productive, than $\theta_{2}$. Firms are assumed to be risk neutral and are operating in competitive markets. The single ability characteristic, $\theta$, is known to the worker, possibly imperfectly, but is not known to the firm. The population proportion of ability worker $j$ with education level $\mathrm{ED}$ is $h\left(\theta_{j}, E D\right)$. Furthermore, it is prohibitively costly for firms to determine $\theta$, the worker's true productivity. However, a worker can signal to an 
employer his ability by investing in education as a signal. Let cost, $c(\theta, E D)$, of obtaining the signal be negatively correlated with productivity and positively correlated with education level. The earnings by a worker depends on the signal obtained by him, $y_{E D}$. Workers are assumed to solve:

$$
\operatorname{Max}_{E D} y_{E D}-c(\theta, E D)
$$

The relevant group to study the impact of the GED credential on earnings is high school dropouts. Among this group, we assume that there are 3 types of workers, i.e. $k=3$, and 2 levels of educational attainment outcomes among high school dropouts: obtaining the General Educational Development credential(G) and no GED (NG). We further assume that the $\theta$ 's map into GED score groups in such a way that both high and low ability workers', $\theta_{1}$ and $\theta_{3}$, test taking outcomes will not be affected by the 1997 passing standard hike while the medium ability workers, $\theta_{2}$, test taking outcome will be affected. That is, $\theta_{1}$ represents the All Pass group, $\theta_{2}$ is the Affected Score Group and $\theta_{3}$ is the All Fail group.

The earnings received for signaling education levels $E D$ are defined as:

$$
y_{E D}= \begin{cases}y_{N G} & \text { if } E D=N o G E D \\ y_{G} & \text { if } E D=G E D\end{cases}
$$

To this point, a person's earnings, or wage, are determined by the beliefs of employers of the meaning of the signal, i.e. the GED credential, and not directly by the ability of the worker. We enrich the model by allowing for wages to also be affected by a vector $\mathbf{X}$ of characteristics that are observable to both the employer and the econometrician (e.g., race/ethnicity) and by a characteristic $v$ that is observable to employers, but not to the econometrician. English language ability is an example of such 
earnings characteristic $v$, which is particularly relevant to Texas with its large immigrant population. We assume that $\theta$ and $v$ are correlated. The wage then is determined by the composition of ability workers in the education group, by $\mathbf{X}$, and by $v$. As stated above, firms do not observe $\theta$ and are consequently going to pay $y_{E D}$ based on the average marginal revenue product, $M R P$, of workers of educational attainment level ED, with a given set of other productivity related characteristics, $\mathbf{X}$ and $v$ :

$$
y_{E D}=\sum_{j} h\left(\theta_{j}, E D\right) M R P\left(\theta_{j} \mid \mathbf{X}, v_{j}\right)
$$

The cost for a worker to obtain the GED credential as a signal includes both the opportunity cost and the "psychic cost" of studying and preparing for the exams and then taking the five test battery of exams. The total cost is a function of ability, and it also depends on the passing standard. In the pre-passing-standard-increase period (Pre-PS), the cost of obtaining a GED is defined as:

$$
c_{G}\left(\theta_{3} \mid \text { Pre-PS }\right)>c_{G}\left(\theta_{2} \mid \text { Pre-PS }\right)>c_{G}\left(\theta_{1} \mid \text { Pre-PS }\right)
$$

This inequality illustrates that it is more expensive for low ability workers to obtain a GED signal than it is for high ability workers. The higher cost of obtaining the GED credential for relatively low ability workers is due to the greater time and mental effort necessary for these individuals to pass the exam compared to relatively high ability individuals. ${ }^{2}$ Furthermore, we assume that in the Pre-PS period obtaining the signal is too costly for some individuals, but affordable for some in the following way:

$$
c_{G}\left(\theta_{3} \mid \text { Pre-PS }\right)>y_{G}^{\text {Pre-PS }}-y_{N G}^{\text {Pre-PS }}>c_{G}\left(\theta_{2} \mid \text { Pre-PS }\right)>c_{G}\left(\theta_{1} \mid \text { Pre-PS }\right)
$$

\footnotetext{
${ }^{2}$ The direct cost associated with obtaining the GED, the GED test fee, varies by testing center, but is quite low. The direct cost of taking the GED exam in Texas can be as low as $\$ 35$ and may even be free in some cases.
} 
According to inequality 5 , in equilibrium the cost to individuals of ability $\theta_{1}$ and $\theta_{2}$ of obtaining a GED is less than the return on that investment, and so we see them with a GED. The $\theta_{3}$ individuals, on the other hand, are willing to invest in the GED, but given their ability, they do not invest sufficiently to obtain the credential. The fact that we see them investing at all and showing up to take the exams can be explained by the fact that they may know their true productivity only imperfectly or by an assumption on their part that the GED exams measure true productivity with some error giving them a non-zero probability of obtaining a GED by chance.

The model and assumptions described above lead to a separating equilibrium. Note that there exist multiple equilibria in the model. If employers change their beliefs sufficiently about what the signal means, a new equilibrium will be reached. However, employers are likely to change their beliefs only if the observed average marginal revenue product changes. Furthermore, it is theoretically possible that the cost of obtaining the signal is either too low or too high so that all individuals, or no individual, would invest in the signal, i.e. a non-separating equilibrium. Given that we observe some dropouts actually receiving the GED credential, while others do not, suggest that neither of these are relevant practical equilibria. Lastly, in the conclusions we discuss the possibility that non-pecuniary factors may be involved in the decision to acquire the GED credential.

The Signaling Value of the GED - Before and After the Passing Standard Increase

An increase in the passing standard, such as the one which took place in 1997, can be viewed as an increase in the cost of obtaining the GED credential (i.e. increased 
preparation time and mental effort necessary to pass the battery of tests). Of course, if some individuals now fail to invest sufficiently to obtain the signal under a higher passing standard the wage received in equilibrium will change, since the composition of the GED group will change. For example, if the cost changes, so that the cost and signaling value of investing in the signal are now $c_{G}\left(\theta_{3} \mid\right.$ Post-PS $)>c_{G}\left(\theta_{2} \mid\right.$ Post-PS $)>y_{G}^{\text {Post }}-y_{N G}^{\text {Post }}>c_{G}\left(\theta_{1} \mid\right.$ Post-PS $)$, $\theta_{2}$ ability individuals will no longer obtain the GED due to the greater effort now necessary to pass the battery of exams ${ }^{3}$. We assume that this is the case and that there exists a group of "marginal" GED candidates who would obtain a GED in the pre-period, but who do not obtain the credential in the post period, i.e. $\theta_{2}$ ability workers.

The composition of GED holders will differ in the pre- and post-passing standard hike periods. In the period before the hike, GED holders consisted of both $\theta_{1}$ and $\theta_{2}$ ability workers, i.e. $G^{\mathrm{Pre}}\left(\theta_{1}, \theta_{2}\right)$, while in the post-period only the highest ability dropouts hold the GED credential, $G^{\text {Post }}\left(\theta_{1}\right)$. As employers learn about the compositional changes the earnings of GED holders will increase since all GED holders now are of the highest ability, $\theta_{1}$, and hence the average marginal revenue product increases. With the addition of relatively higher ability workers, $\theta_{2}$, wages of non-GED holders will also increase since this group's average marginal revenue product also rise. One important group is, however, negatively affected by the passing standard hike, $\theta_{2}$ ability individuals. In our analysis this group will constitute the "marginal" group, which is affected by the passing

\footnotetext{
${ }^{3}$ Here we assume that medium ability individuals still attempt the GED even after the passing standard increase. As with the $\theta_{3}$ workers in both the pre- and the post-1997 period, this requires the assumption that either the GED outcome is uncertain and/or that ability is imperfectly known. Furthermore, we assume that
} 
standard hike with respect to the GED outcome. The new educational attainment equilibrium can be defined as

$c_{G}\left(\theta_{3} \mid\right.$ Post-PS $)>c_{G}\left(\theta_{2} \mid\right.$ Post-PS $)>y_{G}^{\text {Post }}-y_{N G}^{\text {Post }}>c_{G}\left(\theta_{1} \mid\right.$ Post-PS $)$. Note that since both $y_{G}^{\text {Post }}>y_{G}^{\text {Pre }}$ and $y_{N G}^{\text {Post }}>y_{N G}^{\text {Pre }}$ it is unclear whether the GED earnings premium will increase, $y_{G}^{\text {Post }}-y_{N G}^{\text {Post }}>y_{G}^{\text {Pre }}-y_{N G}^{\text {Pre }}$, stay the same $y_{G}^{\text {Post }}-y_{N G}^{\text {Post }}=y_{G}^{\text {Pre }}-y_{N G}^{\text {Pre }}$, or decrease $y_{G}^{\text {Post }}-y_{N G}^{\text {Post }}<y_{G}^{\text {Pre }}-y_{N G}^{\text {Pre }}$.

In the above signaling model, the signaling value of the GED is given by $y_{G}^{\mathrm{PS}}-y_{N G}^{\mathrm{PS}}$, where PS represents whatever passing standard is in effect at the time. However, as discussed above, the ability composition of workers, with and without the GED, will change with a passing standard hike. Our empirical approach outlined below will specifically focus on the signaling value of the GED credential for the "marginal" group. That is, the group whose GED status is most directly affected by the change in the passing standard.

Based on the assumption of three ability types and two educational outcomes, we define the following individual conditional earnings; ${ }^{4}$

$$
\begin{aligned}
& y_{G, 1}^{\text {Pre }}=E\left(y \mid G^{\text {Pre }}\left(\theta_{1}, \theta_{2}\right), \mathbf{X}, v_{1}\right) \\
& y_{G, 2}^{\text {Pre }}=E\left(y \mid G^{\text {Pre }}\left(\theta_{1}, \theta_{2}\right), \mathbf{X}, v_{2}\right) \\
& y_{N G, 3}^{\text {Pre }}=E\left(y \mid N G^{\text {Pre }}\left(\theta_{3}\right), \mathbf{X}, v_{3}\right) \\
& y_{G, 1}^{\text {Post }}=E\left(y \mid G^{\text {Post }}\left(\theta_{1}\right), \mathbf{X}, v_{1}\right) \\
& y_{N G, 2}^{\text {Post }}=E\left(y \mid N G^{\text {Post }}\left(\theta_{2}, \theta_{3}\right), \mathbf{X}, v_{2}\right) \\
& y_{N G, 3}^{\text {Post }}=E\left(y \mid N G^{\text {Post }}\left(\theta_{2}, \theta_{3}\right), \mathbf{X}, v_{3}\right)
\end{aligned}
$$

the effort and study time does not change for a given ability or score group when there is a passing standard change.

${ }^{4}$ For notational simplicity, we ignore the individual subscript $i$ in the presentation of the conditional earnings. 
Note that the conditional earnings are identical for individuals with a given $v$ and a specific GED outcome, holding $\mathbf{X}$ constant. For example, in the pre-period, employers cannot distinguish between $\theta_{1}$ and $\theta_{2}$ workers of a given level of $v$. That is, using our example of English ability, all individuals with the GED and who are fluent in English, holding $\mathbf{X}$ constant, will receive the same wage. However, employers can distinguish between individuals with different levels of $v$, say $v_{1}$ and $v_{2}$, with the same GED outcome. We assume that $v$ and $\theta$ are correlated, plausibly positively, meaning that in our example, higher ability workers are also more likely to be proficient in English than lower ability workers. ${ }^{5}$ The difference in the conditional earnings between workers with a given GED outcome is then due to differences in both $\theta$ and $v$.

Pre- and Post-passing standard hike difference estimators of the total value of the GED may be defined as;

$$
\begin{aligned}
& y_{G}^{\text {Pre }}-y_{N G}^{\text {Pre }}=E\left(y \mid G^{\text {Pre }}\left(\theta_{1}, \theta_{2}\right), \mathbf{X}, v\right)-E\left(y \mid N G^{\text {Pre }}\left(\theta_{3}\right), \mathbf{X}, v\right) \\
& y_{G}^{\text {Post }}-y_{N G}^{\text {Post }}=E\left(y \mid G^{\text {Post }}\left(\theta_{1}\right), \mathbf{X}, v\right)-E\left(y \mid N G^{\text {Post }}\left(\theta_{2}, \theta_{3}\right), \mathbf{X}, v\right)
\end{aligned}
$$

However, neither of these estimators represents the "true" signaling value of the GED for the marginal, $\theta_{2}$, group since neither represents the relevant counterfactual for $\theta_{2}$ individuals. The arguably relevant situation is one in which $\theta_{2}$ workers are observed both with and without the GED in separate labor market regimes with the subsequent compositional changes in the groups with $(\mathrm{G})$ and without $(\mathrm{NG})$ the GED. The problem with the above differences is that the former estimator utilizes a group of non-GED holders that does not include $\theta_{2}$ individuals while the later uses a group of GED holders

\footnotetext{
${ }^{5}$ Of course, $v$ could be negatively correlated with $\theta$ and hence with GED acquisition. This fits with the findings of Heckman and Rubinstein (2001) who find that GED holders have lower non-cognitive skills
} 
that does not include $\theta_{2}$ workers. Instead, for a given passing standard, the "true" GED premium for the marginal ability group can be defined as;

$$
y_{G}^{\mathrm{PS}}-y_{N G}^{\mathrm{PS}}=E\left(y \mid G^{\mathrm{PS}}\left(\theta_{1}, \theta_{2}\right), \mathbf{X}, v\right)-E\left(y \mid N G^{\mathrm{PS}}\left(\theta_{2}, \theta_{3}\right), \mathbf{X}, v\right)
$$

Given the above signaling framework, at a given point in time we do not observe $\theta_{2}$ workers with and without the GED and hence this cannot be directly estimated.

However, given the change in the passing standard, we do observe $\theta_{2}$ individuals with the GED credential in the pre-passing hike period and without the signal in the postperiod. A possible estimator of the GED signaling value is then;

$$
y_{G, 2}^{\text {Pre }}-y_{N G, 2}^{\text {Post }}=E\left(y \mid G^{\text {Pre }}\left(\theta_{1}, \theta_{2}\right), \mathbf{X}, v_{2}\right)-E\left(y \mid N G^{\text {Post }}\left(\theta_{2}, \theta_{3}\right), \mathbf{X}, v_{2}\right)
$$

The difference estimator yields unbiased estimates of the signaling value of the GED credential, for $\theta_{2}$ individuals, under the assumptions that $v$ 's impact on earnings remains constant between the pre- and post-periods ( $v_{2}$ will simply be subtracted out in the difference), or that $v_{2}$ is uncorrelated with the GED outcome. Unbiased estimates using the difference estimator above also require the assumption that there is no pre-post change in the labor market conditions and environment. However, the labor market conditions may indeed be different across periods. This can be alleviated by subtracting out changes in earnings for the groups who were not affected by the passing standard hike, i.e. $\theta_{1}$ and $\theta_{3}$ ability workers, giving us the following difference-in-differences estimators.

$$
\begin{aligned}
{\left[y_{G, 2}^{\mathrm{Pre}}-y_{N G, 2}^{\mathrm{Post}}\right]-\left[y_{N G, 3}^{\mathrm{Pre}}-y_{N G, 3}^{\mathrm{Post}}\right]=} \\
\quad\left[E\left(y \mid G^{\mathrm{Pre}}\left(\theta_{1}, \theta_{2}\right), \mathbf{X}, v_{2}\right)-E\left(y \mid N G^{\mathrm{Post}}\left(\theta_{2}, \theta_{3}\right), \mathbf{X}, v_{2}\right)\right]-
\end{aligned}
$$

than do uncredentialed dropouts. 


$$
\begin{aligned}
& {\left[E\left(y \mid N G^{\mathrm{Pre}}\left(\theta_{3}\right), \mathbf{X}, v_{3}\right)-E\left(y \mid N G^{\text {Post }}\left(\theta_{2}, \theta_{3}\right), \mathbf{X}, v_{3}\right)\right] } \\
& {\left[y_{G, 2}^{\text {Pre }}-y_{N G, 2}^{\text {Post }}\right]-\left[y_{G, 1}^{\text {Pre }}-y_{G, 1}^{\text {Post }}\right]=} \\
& {\left[E\left(y \mid G^{\text {Pre }}\left(\theta_{1}, \theta_{2}\right), \mathbf{X}, v_{2}\right)-E\left(y \mid N G^{\text {Post }}\left(\theta_{2}, \theta_{3}\right), \mathbf{X}, v_{2}\right)\right]-} \\
& {\left[E\left(y \mid G^{\text {Pre }}\left(\theta_{1}, \theta_{2}\right), \mathbf{X}, v_{1}\right)-E\left(y \mid G^{\text {Post }}\left(\theta_{1}\right), \mathbf{X}, v_{1}\right)\right] }
\end{aligned}
$$

Each of these estimators subtracts out the pre-post change in the earnings among nonGED holders and GED holders respectively and will differ depending on how earnings have changed over time. The first difference-in-difference estimator is the preferred one if the general earnings trend of $\theta_{2}$ individuals are more similar to $\theta_{3}$ workers and the latter one is more appropriate if $\theta_{1}$ workers represent the more suitable comparison group. Importantly, if $v$, which is an unobserved characteristic to the econometrician but observable to the employer, is not correlated with the GED outcome, the difference-indifference estimators reduce to estimators of the differences in earnings between GED and non-GED holders in the pre- and post-period respectively;

$$
\begin{aligned}
& {\left[y_{G, 2}^{\text {Pre }}-y_{N G, 2}^{\text {Post }}\right]-\left[y_{N G, 3}^{\text {Pre }}-y_{N G, 3}^{\text {Post }}\right]=\left[y_{G, 2}^{\text {Pre }}-y_{N G, 3}^{\text {Pre }}\right]=\left[y_{G}^{\text {Pre }}-y_{N G}^{\text {Pre }}\right]} \\
& {\left[y_{G, 2}^{\text {Pre }}-y_{N G, 2}^{\text {Post }}\right]-\left[y_{G, 1}^{\text {Pre }}-y_{G, 1}^{\text {Post }}\right]=\left[y_{G, 1}^{\text {Post }}-y_{N G, 2}^{\text {Post }}\right]=\left[y_{G}^{\text {Post }}-y_{N G}^{\text {Post }}\right]}
\end{aligned}
$$

If however $v$ is correlated with the GED outcome, the difference-in-difference estimators does not collapse to the difference estimators. The difference-in-difference estimators will yield unbiased estimates if the change in the passing standard does not change the within group, $\theta_{j}$, relationship between $\theta_{j}$ and $v$ and $v$ 's impact on earnings remain the same in the pre- and post-period or if it changes equally for the relevant $\theta_{j}$ 's (i.e. $\theta_{3}$ and $\theta_{2}$ or $\theta_{1}$ and $\theta_{2}$ ). Using the example of a characteristics which may be observable to the 
employer but not to the econometrician, English ability, we need to assume that English ability is a relevant earnings characteristics, that it is correlated with the defined score groups and that the English earnings premium remains constant in the pre-and postperiod, or if it does change, that it changes equally for the relevant score groups.

\section{Changes in the Labor Market Environment - Earnings Regime}

The above framework assumes that pre-passing standard hike individuals work in a labor market environment where both $\theta_{1}$ and $\theta_{2}$ individuals obtain the GED credential. However, the earnings regime will change in the post-period and $\theta_{2}$ individuals will no longer obtain the signal. In other words, in the (at least immediate) post period, GED holders still consists of both $\theta_{1}$ and $\theta_{2}$ workers. ${ }^{6}$ Over time, the proportion of pre-passing standard hike GED holders will decrease, suggesting that, all else constant, earnings among both non-GED $\left(\theta_{3}\right)$ and GED holders $\left(\theta_{1}\right)$ will gradually increase while the earnings of the marginal group $\left(\theta_{2}\right)$ will gradually decrease. These changes will stop when the compositions are the ones given above (i.e. all non-GED's are $\theta_{2}$ and $\theta_{3}$ and only $\theta_{1}$ hold the GED credential).

We detail our data, research design and empirical models in the next sections.

\section{Data}

This paper brings new and unique data to bear on the GED question in an attempt to better estimate the counterfactual and provide answers to questions about the economic

\footnotetext{
${ }^{6}$ Firms are unable to determine whether GED holders who obtained the credential in the pre-period would also pass in the post-period. Furthermore, we assume employers do not know whether the person attempted the GED in the pre- or post-period.
} 
impact of the GED, particularly regarding the labor market signaling value of this credential. We employ a specially constructed panel data set that contains GED test scores, basic demographic variables, and administrative earnings records in both the preand post-passing-standard-hike periods for a sample of male dropouts who all last attempted the GED exams in Texas either in 1995 or 1997. The key feature of these data is that we have data on GED testers in Texas before and after January 1, 1997, the date on which the passing threshold for the GED in Texas (and several other states) was raised.

The data utilized in this paper are from the Texas Schools Microdata Panel (TSMP). Data from two sources, the Texas Education Agency (TEA) and the Texas Workforce Commission (TWC), were linked to the TSMP data. The TEA data contain information on GED test date, GED test scores, age at test attempt, highest grade attained prior to dropping out of school, gender, ethnicity, GED test language and GED test center. The TWC data contain information on employer reported Unemployment Insurance quarterly earnings. In these data we have quarterly earnings records from the first quarter of 1989 through the last quarter of 2002. When there is no wage record in a quarter, we impute a value of zero. Although our analysis is of the first 20 quarters following the test taking date, we also generate pre-test taking work experience and earnings for the six years prior to attempting the GED.

The sample utilized in this paper is restricted to males who last attempted the GED in either 1995 or 1997, were between the ages of 16 and 40 at the time of the test and did not attempt the GED while incarcerated. We choose 1995 as the period to examine before the passing standard hike because there is some evidence of a change in testing behavior in 1996 in anticipation of the 1997 increase in the scores required to pass 
the GED exams. Simply put, there appears to be less of a rush in 1995 to test before the passing standard changed than is the case in 1996. The sample restrictions we impose yield a sample of 52,251 dropouts who last attempted the GED exams in either 1995 or $1997^{7}$

\section{Descriptive Statistics}

Sample descriptive statistics and graphs are presented in Tables 1 and 2, and Figures 1 and 2 . Figure 1 plots the quarterly earnings by quarters from the time individuals attempted the GED, both before and after, by GED status. The raw quarterly earnings of eventual GED holders and GED candidates who will, eventually, fail the exams appear similar in the quarters prior to attempting the GED, with some relatively weak indication of slightly higher earnings in the quarters immediately before taking the GED among eventual passers. About a year after the GED attempt, the unadjusted earnings of those who passed the exams, and hence were awarded the credential, begin to diverge from the uncredentialed GED candidates. The patterns in the Texas data are similar to what has been observed in other UI quarterly earnings data on GED candidates. In particular, they are very close to what Tyler (2004) found using data from Florida. Two differences are the flattening of the earnings profile of both groups just prior to attempting the GED and the increase in mean quarterly earnings for both groups immediately after the GED attempt. One possible reason for the pre-test flattening of the profile is test preparation, in which individuals spend less time working in the quarter

\footnotetext{
${ }^{7}$ We say "last attempted," because upon failing the GED exams, a dropout can, with certain minimal restrictions, retake the GED battery. We classify individuals into last-attempt years based on GED data as of December 31, 2000.
} 
before, and of taking, the GED test. This is consistent with the observed proportion of individuals with positive earnings, i.e. roughly employment rates, which we discuss next.

Figure 2 shows the percentage in each group, successful and unsuccessful GED candidates, who have positive earnings in each quarter around the GED attempt. Unlike the raw mean earnings profiles of Figure 1, the profiles in Figure 2 indicate that eventual GED holders were more likely to be employed in the quarters before the GED attempt than were candidates who would eventually fail the GED exams. Also, the employment advantage does not appear to widen after the successful candidates were awarded their GED. The higher pre-test taking employment rates among eventual GED passers suggest that this group have accumulated greater work experience prior to taking the GED. This may partially explain their relatively greater earnings growth, and levels, in the period after having received a GED credential.

Table 1 provides information on GED candidates in Texas in the two testing years, 1995 and 1997. The central message of the table is that the two cohorts of candidates appear quite similar on the observable individual characteristics. There are however some small but statistically significant differences. GED test takers in the 1997 sample completed slightly less schooling, are somewhat younger and consist of fewer African-Americans and more Spanish test takers. The table shows that test scores are significantly higher among 1997 test takers relative to 1995 test takers. Given our discussion above of a simple signaling model, it is not surprising that the test scores are higher since the implicit cost have increased with the higher passing standard and is likely to deter, in particular, some medium ability individuals from attempting the GED. Also, as might be expected, the percentage who passed the exams declined-ten percent 
fewer candidates passed in 1997, after the passing standard was raised, than in 1995. One factor that should not go unnoticed is that the number of dropouts who attempted the GED exams in 1997 was substantially lower than in 1995. This observation has potential implications for our identification strategy, a point we address in a later section.

Table 2 displays information for the six distinct groups created by the passing standard change. The groups of particular importance, given our empirical strategy, are the treatment and comparison groups, i.e. those in the "affected score group". To validate our identification strategy, the assignment into these groups needs to be random, or more specifically, in the models defined below, assignment into the groups, controlling for observables, including differences across the other pre- and post-passing standard change groups, must be uncorrelated with the disturbance term.

According to Table 2, the treatment and comparison groups appear quite similar across the dimensions on which we have data. ${ }^{8}$ There are however some differences. For example, the percentage African-Americans is slightly larger in the comparison group. The comparison group also has slightly greater pre-test-taking work experience, about two-thirds of a quarter, and higher pre-test taking quarterly earnings. A difference between the 1997 and 1995 group pre-test taking earning also exists for the failing groups, i.e. groups 1 and 2, in the two years prior to attempting the GED, although it is smaller. The test score statistics in Table 2 suggests that the score distribution within the affected score group did not change appreciably. There appears, however, to be a slight within group shift in the score distribution to the right among the All Fail group.

\footnotetext{
${ }^{8}$ Of course, these two groups have similar test scores by construction.
} 
It should also be pointed out that the sample size of the treatment and comparison groups are quite different, with the latter being smaller. There are at least two explanations for this 1995 to 1997 drop in the sample size of the affected score group.

The first explanation lies in the necessary definition and restriction of test takers. We have restricted our sample to individuals who last attempted the GED in either 1995 or 1997. A test taker in this score group who took the exam in 1995 has no incentive to come back and test again since he has already received high enough scores to obtain the credential. However, a 1997 test taker in this score group is quite close to passing but did not receive the credential. Some individuals with scores in this range are likely to return later to try again. If these individuals returned for another attempt in 1998 or later, they would be excluded from our sample. To address this potential complication, we will perform robustness tests, including a restriction of our sample to individuals who only attempted the GED in either 1995 or 1997.

A second explanation is that some individuals who would be potential affectedscore-group members in 1997 are deterred by the higher passing standard and never attempt the GED. To the extent that these potential "no shows" are not a random subsample from the affected score group, their absence from the estimation could bias our results. A third, and related, explanation is that individuals who attempted fewer than all five exams in 1997 were placed in the "all failer" group in our analysis. To the extent that some of these individuals would have been in the affected score group had they completed all of the exams, they are essentially "mis-assigned" by us. Again, to the extent that these individuals are a non-random subsample of the affected score group, 
their potential "mis-assignment" could bias our estimates. We return to these two related, potential sources of bias later in the paper.

\section{Empirical Specifications}

\section{Natural Experiment:}

Lacking a true experiment that would generate exogenous variation in GED status, we exploit the 1997 change in GED passing standards in Texas as a natural experiment that simulates random assignment of the credential. We will utilize the six groups defined above.

There are two key assumptions in our identifying strategy. The first is that any difference in outcomes between the individuals in the treatment and comparison groups are solely the result of differences in GED status and in the years in which they tested and, hence, entered the labor market. The second key assumption is that the individuals in group 1 relative to group 2 and those in group 5 relative to group 6 differ only in the years in which they attempted the GED exams, and as a result these individuals can be used to purge the treatment group versus comparison group contrast of any differences related to whether they attempted the GED before or after the change in the passing standard. These assumptions, or restrictions, can be relaxed somewhat and still yield unbiased estimates of the signaling value of the GED. As long as the assignment into the defined score groups is uncorrelated with the disturbance term, the estimates of the GED effect are unbiased.

The difference-in-differences estimator that captures this idea is given by the following specification; 


$$
\begin{aligned}
y_{i t} & =\alpha_{0}+\text { YrsPost }_{i t} \boldsymbol{\alpha} \\
& +\beta_{0} \text { Before }_{i}+\text { YrsPost }_{i t} * \text { Before }_{i} \boldsymbol{\beta} \\
& +\delta_{0} A_{S G_{i}}+\text { YrsPost }_{i t} * A S G_{i} \boldsymbol{\delta} \\
& +\gamma_{0} \text { ASG }_{i}{ }^{*} \text { Before }_{i}+\text { YrsPost }_{i t} * A S G_{i} * \text { Before }_{i} \gamma \\
& +\eta_{0} \text { AllPass }_{i}+\text { YrsPost }_{i t} * \text { AllPass }_{i} \boldsymbol{\eta} \\
& +\lambda_{0} \text { AllPass }_{i} * \text { Before }_{i}+\text { YrsPost }_{i t} * \text { AllPass }_{i} * \text { Before }_{i} \boldsymbol{\lambda} \\
& +\mathbf{X}_{i t} \boldsymbol{\pi}+\text { Time }_{t} \boldsymbol{\tau}+u_{i t}
\end{aligned}
$$

where;

$$
\begin{aligned}
& y_{i t} \quad=\quad \text { Quarterly earnings for individual } i \text { at time } t \text {. } \\
& \text { AllPass }_{i} \quad=\quad \text { dummy variable indicator for those whose score would place them } \\
& \text { above the passing threshold either before or after the change in the } \\
& \text { passing standard, } \\
& A S G_{i} \quad=\quad \text { dummy variable indicator for those whose scores place them in the } \\
& \text { affected score group, } \\
& \text { Before }_{i} \quad=\quad \text { dummy variable indicator for having taken the GED exams before } \\
& \text { the passing standard was raised, i.e. } 1995 \text { test takers, } \\
& A S G_{i} * \text { Before }_{i}=\quad \text { identifies individuals in the treatment group-individuals in the } \\
& \text { affected score group who have a GED, } \\
& \text { YrsPost }_{i t} \quad=\quad \text { a vector of dummy variables indicating whether earnings were } \\
& \text { measured in the second, third, fourth or fifth years after the GED } \\
& \text { attempt, } \\
& \mathbf{X}_{i t} \quad=\quad \text { matrix containing a set of individual control variables including } \\
& \text { age, highest grade completed, race/ethnicity, pre-test taking } \\
& \text { earnings and experience, }{ }^{9} \\
& \text { Time }_{t}=\quad \text { vector capturing time fixed effect. }
\end{aligned}
$$

It is straightforward to show that, given this specification, the parameters yielding the GED signaling value estimator, utilizing the group of failers as the comparison group, 
are $\gamma_{0}$ and $\gamma_{0}+\gamma_{t}$, the first of which is the difference in mean outcomes between the treatment and comparison individuals in the first year after the GED attempt, after the 1995 to 1997 change for the failers have been differenced out. In other words, this is the difference-in-differences estimator for the first post-attempt year's earnings, under the assumption that low ability workers' pre-post changes in earnings most closely resembles the overall changes in the labor market earnings of the medium, or marginal, ability group. The parameter $\gamma_{0}+\gamma_{t}$ is the difference-in-differences estimator for the $t^{\text {th }}$ year's earnings. Similarly, the parameters of interest using the all passer group to purge time effects are $\gamma_{0}-\lambda_{0}$, for the first year after taking the GED exam and $\left(\gamma_{0}+\gamma_{t}\right)-\left(\lambda_{0}+\lambda_{t}\right)$ represents the estimator for the $t^{\text {th }}$ year since taking the GED.

OLS estimates of the parameters from this specification will be unbiased if, controlling for relevant changes in the labor market environment, the comparison groups accurately estimates the counterfactual of what would have happened to the treatment group had they not been awarded a GED.

It is worth reemphasizing here that by construction, the members of the treatment and comparison groups have the same GED test scores. Thus, to the extent that GED test scores capture dropouts' levels of human capital, $\gamma_{0}$ and $\gamma_{0}+\gamma_{t}$ (alternatively, $\gamma_{0}-\lambda_{0}$ and $\left.\left(\gamma_{0}+\gamma_{t}\right)-\left(\lambda_{0}+\lambda_{t}\right)\right)$ estimate the signaling value of the GED. Specifically, and importantly, our estimates represent the signaling value of the GED for "marginal" GED holders, i.e $\theta_{2}$ workers or put differently, individuals who barely passed the GED exam. This is similar to the estimation strategy used by Tyler, Murnane, and Willett (2000),

\footnotetext{
${ }^{9}$ Pre-test experience is measured as the number of quarters in the six years prior to testing in which nonzero earnings are recorded. Pre-test earnings is a vector of six variables representing the annual earnings
} 
who utilize state variation in passing standards. To the extent that there is a human capital component to the GED credential, the difference-in-differences estimator will underestimate the total impact of the GED on earnings. Similarly, if employers are able to infer productivity of individuals with the GED credential based on observable characteristics, i.e. the GED outcome and $\mathbf{X}$ are correlated, our estimators will represent the average GED signaling value across $\mathbf{X}$ for "marginal" passers. Similar arguments can also be made for the Tyler, Murnane and Willett (2000) research approach.

\section{OLS Specification:}

As a first step in the empirical work, we fit simple OLS models to establish that the Texas data do not generate unique patterns relative to earlier work. Our OLS specification is;

$$
\begin{aligned}
y_{i t}= & \beta_{0}+\beta_{1} \mathrm{GED}_{i}+\beta_{2} \text { Before }_{i}+\text { YrsPost }_{i t} \gamma+\text { YrsPost }_{i t} * \mathrm{GED}_{i} \tau_{t} \\
& +\mathbf{X}_{i t} \nu+\text { Time }_{t} \alpha+\varepsilon_{i t}
\end{aligned}
$$

where $\mathrm{y}$ is the quarterly earnings for individual $i$ in year-quarter, $t$ is the quarter after the GED attempt in which earnings are measured and $t \in(1,2, \ldots, 20), G E D$ is an indicator variable for possessing a GED, Before is an indicator variable for attempting the GED in 1995, YrsPost is a vector of dummy variables indicating whether earnings were measured in the second, third, fourth or fifth years after the GED attempt. The interaction between GED and YrsPost allows earnings to grow differently for GED-holders and non-GED-holders. The matrix $\mathbf{X}$ contains the set of individual control variables defined above as well GED scores. Time is a vector of year-quarter dummy variables, i.e. time fixed effects that control for macro economic conditions.

(sum of the year's four quarters of earnings) in each of the six years prior to testing. 
There are two interpretations that can be given to estimates based on the OLS specification. First, to the extent that the $\mathbf{X}$ matrix, including GED test scores, captures an individual's stock of human capital, $\beta_{1}$ is an estimate of the signaling value of a GED on first year earnings, and $\beta_{l}+\tau_{t}$ is an estimate of the signaling value of the GED on earnings in the $t^{\text {th }}$ year. If one thinks that the matrix $\mathbf{X}$ and GED test scores capture only some portion of an individual's level of human capital, then $\beta_{l}$ is an estimate of some combination of the signaling value plus the return to the unexplained (by $\mathbf{X}$ and GED test scores) portion of human capital of a GED on first year earnings, and $\beta_{l}+\tau_{t}$ are estimates

of the same for the $t^{\text {th }}$ year. The important point here is that under either interpretation, $\beta_{1}$ and $\beta_{1}+\tau_{t}$ are unbiased estimates of the causal impact of the GED only if the variable $G E D$ is uncorrelated with $\varepsilon$. The latter is however counter to our simple signaling model in which earnings is also function of unobserved heterogeneity, i.e. $v$. The assumption that $\operatorname{COV}(G, v)>0$ would lead to an upward bias of the OLS estimator of the GED signaling value.

\section{Fixed Effects Specification:}

The next two specifications are comparable to those used in earlier research, specifically Tyler (2004). These specifications attempt to address potential unobserved heterogeneity of dropouts who do and do not obtain a GED, and we include them here to establish that the Texas data yield similar results to Tyler (2004). The first of these specifications is a fixed effects model which controls for time invariant individual unobserved heterogeneity. The specification is;

$$
\begin{aligned}
y_{i t}= & \beta_{i}+\beta_{1} \mathrm{GED}_{i t}+\text { YrsPost }_{i t} \gamma+\text { YrsPost }_{i t} * \operatorname{GED}_{i} \tau_{t} \\
& +A g e_{i t} \lambda_{0}+A g e_{i t}^{2} \lambda_{1}+\text { Time }_{t} \alpha+\varepsilon_{i t}
\end{aligned}
$$


Note that in this specification, to be able to identify the GED effect, we include observations prior to the GED attempt. As opposed to all other models estimated, where $t=1,2, \ldots, 20$, we now add in observation for the six quarters before the person took the GED, i.e. $t=-6,-5, \ldots, 20$. This implies that the variable $G E D$ is set to zero in all quarters before the GED attempt for all individuals and one in the quarters after the GED attempt for those who receive passing scores. In this specification $\beta_{i}$ is the individual fixed-effect. The vector YrsPost is defined as in the above simple OLS specification. The model also includes time fixed effects and controls for age, which is the only time varying individual variable in our data. If unobserved individual heterogeneity is time invariant, as is assumed in our simple signaling model, the estimates of $\beta_{l}$ and $\beta_{l}+\tau_{t}$ will be unbiased. However, if unobserved heterogeneity is time-varying, possibly reflecting a positive change in motivation which coincides with the decision to take the GED, the fixed-effects specification will also yield a biased estimate of the causal impact of the credential.

\section{Regression Discontinuity Specification:}

Tyler (2004) also takes advantage of the fact that there is a cutoff, or discontinuity, in the average score, holding minimum score at 40 on each of the five components, in order to obtain the GED credential. In our Texas data this strategy can most clearly be applied to the individuals who took the GED in 1997 since there does not exist an equally well defined discontinuity prior to the passing standard hike. ${ }^{10}$ Hence in this specification, we limit our sample to individuals who attempted the GED in 1997;

\footnotetext{
${ }^{10}$ A 1995 cutoff can be constructed using individuals who have at least one exam score below 40. Using just these individuals, a regression discontinuity would be examined around a mean score of 45 . The problem with using this 1995 passing standard to examine a potential regression discontinuity is that there
} 


$$
\begin{aligned}
y_{i t}= & \beta_{0}+\beta_{1} \mathrm{GED}_{i}+\beta_{2} \text { MeanScore }_{i}+\text { YrsPost }_{i t} \gamma+\text { YrsPost }_{i t} * \operatorname{GED}_{i} \tau_{t} \\
& +\mathbf{X}_{i t} \nu+\text { Time }_{t} \alpha+\varepsilon_{i t}
\end{aligned}
$$

The model to be estimated given our third specification is similar to the OLS specification except that we include mean GED score, as opposed to all individual scores. Furthermore, the model is fitted using test takers who scored a minimum of 40 and whose mean score was between 40 and 50 . The latter restriction is imposed since the relationship between earnings and average scores may not be linear over the full range of mean scores. Unbiased estimates of $\beta_{1}$ and $\beta_{l}+\tau_{t}$ in this model rest on the assumptions that in a narrow range around the passing cutoff the conditional earnings-mean-score relationship is linear and captures the relevant unobserved heterogeneity, and that any vertical shift in the regression line at the cutoff is due solely to acquisition of the credential. We note that while the fixed effects specification of equation 2 estimates the total impact of the GED, regression discontinuity estimates based on equation 2 capture the signaling value of the credential.

\section{Empirical Results}

We begin the empirical investigation by fitting models based on variations of the simple OLS specification. Coefficient estimates and test statistics are displayed in Table 3. The estimated GED effects in Table 3 are summarized in Table 4 across the years, including standard errors and tests of the null hypothesis of no GED effect.

Results from Model 1 in column 1 are from a simple model that includes time fixed effects, to control for differences in macro economic conditions, and controls for 
highest grade attained, age, race/ethnicity, whether or not the Spanish language version of the GED was taken and whether the test was taken in 1995 or 1997. These baseline results indicate that in the first year following the GED attempt, the mean quarterly earnings of GED holders are somewhat higher than those of dropouts who attempted, but failed, the exams. However, by the fifth year following the GED attempt, the mean quarterly earnings of GED holders are about $\$ 423(\$ 60+\$ 363)$ higher than those of the individuals who failed the GED. A rather substantial change in the estimates appears in Model 2 when controls for pre-test taking work experience and earnings are included. The estimates now indicate significantly lower earnings for GED holders in the first year after taking the GED, by $\$ 76$. This is reversed in the preceding years and in the fifth year following the GED attempt, the quarterly earnings advantage is about $\$ 288$. This suggests that almost $1 / 3$ of the estimated GED earnings premium is due to differences in pre-test taking labor market outcomes between men who pass and fail the test.

Model 3 in Table 3 add controls for GED test scores. When GED test scores are added, the estimated GED effect falls by approximately 20 percent. Nevertheless, Model 3 estimates still indicate that by the fifth year after the test attempt, GED holders earn about \$234 more per quarter than do observationally similar dropouts lacking the credential. To the extent that GED test scores capture the human capital of GED examinees, these results can be interpreted as the signaling value of the GED. Under this interpretation, roughly 80 percent of the fifth year GED advantage estimated using Model 2 is due to the signaling component of the GED. Of course, since we have no information on pre-GED test scores, we do not know how much, if any, of the remaining 20 percent is 
the result of human capital related to GED preparation versus human capital that GED examinees already possessed before they decided to attempt to acquire the credential.

The fixed effects model specification is presented as Model 4 in Tables 3 and 4. The results indicate a strong GED effect on earnings. In fact, the estimates suggest a statistically significant immediate earnings advantage in the first year since taking the GED of about $\$ 220$. By the fifth year the GED premium has grown to roughly $\$ 426$.

The last model, Model 5 in Tables 3 and 4, utilizes the regression discontinuity strategy and the 1997 sample. The estimated impact of the GED on earnings is substantially smaller than in the fixed effects model and somewhat less than the simple OLS estimates indicate. There appear to be no effect in the first year after taking the GED but by the fifth year GED holders earn a statistically significant $\$ 190$ more per quarter than do dropouts who did not obtain the credential.

We next turn to a comparison of the results in tables 3 and 4 to previous findings of the impact of the GED on earnings, primarily to determine if the Texas data can generate similar results to earlier studies. In particular, we want to see if our results are close to those in Tyler (2004) that are based on GED examinees in Florida. Like our Texas data, the Florida data used in Tyler (2004) also contain demographic information, GED test scores, and UI quarterly earnings. Two comparisons are important. First, across all of the specifications represented in Tables 3 and 4, except for the regression discontinuity specifications, our estimates in Texas are quite similar to those found by Tyler. The OLS and fixed effects estimates indicate that four to five years after taking the GED, individuals who passed the exam display higher quarterly earnings by about 10-17 percent. Data used in the Tyler paper had the slight advantage of an additional 4 quarters 
of post-GED attempt UI wage information, and the estimated differences were $\$ 266$ and $\$ 310$ in the fifth and sixth years following the GED attempt, respectively.

Regarding the regression discontinuity results, the $\$ 190$ GED earnings advantage we find after five years represents about an eight percent increase over the $\$ 2,500$ mean quarterly earnings that unsuccessful GED examinees exhibit five years after the attempt (see Figure 2). This is about half of the roughly twenty percent effect Tyler finds in Florida based on the same regression discontinuity design. We return to a discussion of these regression discontinuity estimates at the end of the paper.

The second general comparison between our results and the earlier Tyler work worth noting is that similar to Tyler (2004) and others (Tyler, Murnane, and Willett 2000), we find that examining the first years after the GED attempt will typically fail to reveal any substantive GED earnings advantage; it typically takes at least three years for substantively large and statistically significant results to appear. ${ }^{11}$ These results indicate that estimates based on the Texas data quite closely replicate results using similar data from Florida.

Of course regardless of the data source, estimates based on any of our specifications are only as good as the assumptions upon which they rest. The simple OLS estimates may be biased if the GED scores variables do not adequately capture productivity related unobserved heterogeneity, including ability and motivation. Estimates based on the fixed effects specification will be biased if there are time-varying, unobserved differences between GED candidates who do and do not obtain the credential. The validity of the regression discontinuity approach hinges on whether or not

\footnotetext{
${ }^{11}$ Tyler, Murnane, and Willett (2000) also find that GED effects grow over time and are often negligible in the first years after the attempt.
} 
the earnings-mean score relationship is linear in the vicinity of the passing score cutoff and whether any unobservables related to earnings are smooth around the vicinity of the passing score cutoff. In short, identification in all of these approaches rests on untestable assumptions.

Identification using the natural experiment in Texas also rests on untestable assumptions. Namely, that there are no differences in who decides to attempt the GED in the pre- and post-passing-standard-change regimes and no differences in test preparation across these regimes. On the other hand, an advantage of the natural experiment is that there is a clear and arguably exogenous source of policy variation that is related to who does and does not receive a GED in Texas

\section{Natural Experiment Results}

Given that there are two possible comparison groups to our "marginal" group, individuals whose score were not sufficiently high to pass under either passing standard (All Fail) and individuals whose score were sufficiently high to pass under either passing standard (All Pass), our specification yields two, potentially, different estimators of the GED signaling value. As Tables 5 and 6 reveal, there are relatively small differences in the point estimates between these two estimators. Our discussion below will refer to the point estimates utilizing the All Pass comparison group.

Model 1 in Table 5 presents estimates from the "pure" natural experiment. Based on Model 1, GED holders in the treatment group earn approximately \$264 less in the first post-attempt year than do members of the comparison group who have the same GED test scores, a result that is statistically significant. This may be because newly minted GED 
holders are engaged in more post-attempt post-secondary education, training, or job search than are comparison group members lacking a GED. ${ }^{12}$ As the companion results in the first column of Table 6 show, this negative effect becomes small enough in subsequent years so that it is not statistically significant. The overarching message of column one is, however, that estimates of the impact of the GED on earnings from the natural experiment fail to find any positive effect.

If the natural experiment is doing a good job at pseudo-randomization, estimates should change little when observable control variables are added. The evidence on this in Table 5 is somewhat mixed. Estimates from Model 1 change little when time fixed effects are added in Model 2 or when age, schooling, and ethnicity are added in Model $3 .^{13}$ The largest changes in the estimates occur when pre-test-taking work experience and earnings are added in models 4,5 , and 6 , and all of the change associated with adding these controls accrues to the first year GED effect. From Model 3 to Model 6 the first year negative GED "effect” decreases by slightly less than 30 percent. Even with this less negative first year effect, however, inferences about the impact of the GED remain unchanged from Model 3 to Model 6. In fact, the conclusion one would draw from the estimates in Model 1, that GED holders display lower earning in the first year after attempting the GED and earn no premium from the credential in subsequent years, holds across all models. As discussed above, the lower earnings in the first year may be due to a composition effect where relatively more productive GED holders enroll in some

\footnotetext{
${ }^{12}$ We note that while previous work suggests that GED holders only accumulate 0.4 mean total years of post-secondary education (Murnane, Willett, and Tyler 2000), this same work shows that up to 30 percent of the GED holders in the data earned at least one college credit.

${ }^{13}$ Note that the estimates using the All Fail group appear more sensitive to adding controls for age, schooling and ethnicity than the estimates utilizing the All Pass group as the comparison group. This is not
} 
schooling in the first year after receiving the GED diploma. It is also possible that upon successfully obtaining the GED credential, an individual's reservation wage may increase. As a result, the job search process is likely to take longer as the person is now requiring a higher wage to accept a job offer. Nonetheless, the results strongly indicate that there is no evidence of a positive impact of the GED on the earnings of male dropouts when the effect is identified through the natural experiment of the passing standard change.

\section{Robustness Checks}

Clearly, the above presented results warrant thorough robustness checks. We do this by first examining the validity of the natural experiment. Next, we see if the results can be generalized or appear to be specific to some groups in our sample population.

An important advantage with our data is that we can investigate the validity of the experiment by analyzing pre-intervention differences between treatment and comparison groups. While Table 2 indicates that there are statistically significant pre-intervention earnings differences between the 1995 and 1997 affected score groups (\$1,089 versus \$1,247), these differences could be the result of differing labor markets between 1994 and 1996 and/or differences in observable characteristics between the 1995 and 1997 affected-score-group members. To account for these potential differences, we estimate a difference-in-differences model similar to Model 3 in Table 5 using only observations from the four quarters prior to the GED attempt, i.e., the year before the GED attempt. The estimated earnings difference the year before taking the GED between the treatment

very surprising given that we also observed somewhat greater within group pre-post changes for the All Fail group relative to the All Pass group. 
and comparison groups indicate that the treatment group earned roughly $\$ 75$ more than the comparison group. However, the standard error is quite large, $\$ 48$, suggesting no preintervention difference between the two groups. ${ }^{14}$ The results are virtually unchanged if we extend the pre-test taking period to the immediate two years before the test was taken. These results suggest that the treatment and comparison groups were similar in the pretreatment years, a first test for the validity of any experiment or natural experiment.

As stated earlier, the difference in the sample size between the treatment and comparison group suggests that there may be some non-random assignment into these groups. There are three potential and non-mutually exclusive explanations for the smaller relative size of the comparison group, and we examine the potential impact of each in turn. First, the 1995 test takers in the affected score group had no incentive to take the GED in later years since their score qualifies them for the credential. However, 1997 testers whose scores would place them in the affected score group failed to obtain a credential and thus had an incentive to retake the GED exams. Any of these potential comparison group members who chose to retest in 1998 or later would not be included in our sample. Thus, the 1997 affected score group members may be a selective group of individuals since they did not return to try to obtain the credential again.

To address this concern we re-estimated the models shown in Table 5 and 6 using a restricted sample including only individuals who attempted the GED once, either in 1995 or in $1997 .{ }^{15}$ The results for Model specification 6 are presented in the first column of Table 7. The results are quite similar to the ones shown in Table 6. For example, the

\footnotetext{
${ }^{14}$ These estimates use the all-passer group for the second difference. Estimates using the all-failer group for the second difference are similar.
} 
estimated first year difference between the treatment and comparison group for Model 6 specification, using the All Pass group as the comparison group, is $-\$ 197$ for the sub sample of test takers who only attempted the GED once, compared to -\$172 in the "full" sample. The estimated GED effects in subsequent years become positive but are statistically insignificant.

A second reason for the smaller comparison group has to do with potential behavioral changes associated with the change in passing standard. While the imposition of the passing standard hike in Texas was surely exogenous to Texas, the behavior of GED preparation providers, GED examinees, and potential GED examinees may have been influenced by the passing standard change in ways that influence our results.

Figure 3 plots trends over time in the number of GED examinees in Texas and in Florida. Florida, of course, is a state that did not face a passing standard hike in 1997 as did Texas, though the standard was raised slightly in Florida in June of 1998, again in July of 1999, and again in July of 2000. ${ }^{16}$ The trend line in Texas indicates that there was a substantial increase in the number of GED examinees in Texas in 1996, the year prior to the passing standard hike, followed by a substantial fall off in the number of GED examinees in 1997, the year immediately after the passing standard hike. The 1996 increase in test takers is consistent with anecdotal evidence that GED preparation providers were encouraging GED candidates to attempt to acquire the credential before the higher standards went into effect. This is the primary reason that we choose to use 1995 as a "before" period in our difference-in-differences estimates; we were concerned

\footnotetext{
${ }^{15}$ Specifically, the restrictions that the test taker only attempted the GED once, in 1995 or 1997, covers the period January 1, 1990, the earliest year our data on GED test takers cover, to December 31, 2000, the latest date our GED test score data span.
} 
that the pool of GED examinees in Texas was different in unobservable ways in 1996 as the run up to the January 1, 1997 deadline loomed.

On the other hand, we are not able to account for is the potentially different pool of GED examinees from which we draw our comparison group - those who chose to attempt the GED exams after the passing standard hike was in place in 1997. The sharp drop in the number of testers in Texas that occurred between 1994-1996 and 1997 suggests that those who decided to attempt to obtain a GED in 1997 may be different than GED examinees of the near prior years. Of primary concern for us is whether those who tested and just failed in 1997, our comparison group, are different in unobservable ways from those who tested and passed with the same scores in 1995, our treatment group. In particular, if the reduced pool of dropouts who did decide to attempt a GED in 1997, in spite of the higher standard, have on average more productive unobservable traits than the pool of 1995 examinees, then our natural experiment estimates would be downwardly biased. Thus, if individuals in the 1997 comparison group have more motivation, more determination, are less deterred, etc., then we would expect our results to be downwardly biased.

It is important to note that if these types of unobservable differences exist for everyone in the 1995 and 1997 groups, then there is not a problem, as the difference-indifferences estimator will account for them. What is a problem, however, is if the individuals who are nearest the passing cutoff tend to have more unobservable productivity in 1997 than in 1995 than do those who are farther from the cutoff. For example, if it is the case that most of the reduction in testing numbers that occurred in

\footnotetext{
${ }^{16}$ In June of 1998 Florida GED candidates had to score a minimum of 42 and a mean of 45 to be awarded a GED. In July of 1999 the minimum allowable score was raised to a 44, and in July of 2000 the minimum
} 
Texas between 1995 and 1997 occurred because of the decision not to test by those who would tend to score close to the passing standard, while there were few changes at the upper and lower ends of the skill distribution in the propensity to test, then our results could be biased. The observation, from Table 2, that there are substantial changes in the sample size of the affected score group between 1995 and 1997, while there are essentially no changes in the 1995-1997 sample sizes of the all-failer and all-passer groups is consistent with a scenario whereby most behavioral changes were occurring around the passing score cutoff.

Examining the extent to which the 1997 affected score group is systematically different from the 1995 affected score group is not something that we can do directly. One approach we could take would be to restrict the other groups, the all-failers and the all-passers, to those who were closer to the affected score group in terms of their GED test scores. That is, use only "high failers" and "low passers" in the second difference of the difference-in-differences estimator. Our confidence in this robustness check is contingent upon how well these high-failer and low-passer subsamples mirror any changes in the affected score group sample between 1995 and 1997. Unfortunately, the large drop in the 1995 to 1997 affected score group sample size is not mirrored in either the high-failer or low-passer subsamples; these more narrowly defined subgroups have about the numbers of test takers in 1997 as in 1995. As a result, it is not clear that either of these groups could control for unobservable changes in the affected score group between 1995 and 1997 that might result from behavioral changes in who attempts the tests. Nevertheless, under the "Low-pass/High-fail" column of Table 7, we present

allowable score was a 45 giving Florida the highest GED passing standards in the nation. 
estimates using these more narrowly defined all-passer and all-failer groups that are similar to our full sample estimates.

A third explanation for the drop in the affected score group sample size between 1995 and 1997 is that "potential" 1997 affected score group members get "mis-assigned" by us in the construction of the different groups. In particular, anyone who did not take all five of the GED exams as of 1997 were assigned to the "all failer" group. There are potentially individuals thus assigned who, if they were to attempt all five tests, would have scores that would place them in the 1997 affected score group. If these "misassigned" individuals are, on average, less productive than the observed 1997 affected score group, our difference-in-differences estimates are downwardly biased. Unfortunately, we have no good way of directly examining this potential source of bias. However, the natural experiment results using a restricted sample of individuals who took all five exams reveal no appreciable differences in the results compared to the ones presented in Tables 5 and 6.

Thus, sample selection between 1995 and 1997 into who does or does not decide to attempt the GED exams, given the passing standard, is a worrisome source of bias for our natural experiment estimates. One final method for examining this issue is to refit Model 6 replacing the 1997 test takers with 1998 test takers. Given that our data include earnings information up until the fourth quarter in 2002, we can only track 1998 test takers post-test taking earnings for four years. As is shown, in column 3 in Table 8, the results using 1998 test takers are quite similar to the ones we obtained using 1997 test takers. However, given that Figure 3 only indicates a slight rebound in the number of 
GED examinees between 1997 and 1998, it is not clear that these estimates are purged of any bias that might be associated with the 1997-based estimates.

We next turn to an investigation of whether the finding of no positive GED effect may be specific to certain groups in our sample. Previous research by Tyler, Murnane and Willett (2000) finds no evidence that non-white dropouts who obtain the GED credential earn more than statistically similar non-whites who failed to receive passing scores. To address whether our results are driven by the relatively large proportion of non-white minorities in our sample, close to 60 percent, we estimated Model 6 separately for whites and non-whites. The results are presented in the fourth and fifth result columns in Table 7. The results for the two groups are sufficiently similar that one would draw the same conclusions regarding the impact of the GED on earnings for both groups, lower earnings in the first year and no effect in the subsequent years.

Since the sample used in Tyler, Murnane and Willett (2000) consisted of young dropouts, between the ages of 16-21, a positive GED effect may be specific to this age group. To test whether our data, and approach, may mask these effects since we include males between the ages of 16 and 40, we fitted Model 6 for a sample of 16-21 year old males. The results are shown in column six, Table 7. The estimates do not suggest that there are any differences between the relatively younger dropouts and their older counterparts since the results are very similar to the ones for the 16-40 age group. ${ }^{17}$

The above sensitivity analyses, while not perfect, are all supportive of our main results, suggesting that the strategy using the natural experiment to identify the signaling value of the GED credential is reasonably robust. Furthermore, the finding of no 
statistical difference in pre-test taking earnings between the treatment and comparison groups is consistent with an assumption that the 1997 affected score group serves as a good comparison group for the 1995 affected score group.

\section{Summary and Conclusions}

\section{Reconciling differences}

The natural experiment estimates in this paper differ from recent results in the literature which indicate a positive impact of the GED on the earnings of low skilled dropouts. In particular, Tyler, Murnane, and Willett (2000) used national data and a natural experiment similar to that used in this paper to estimate the impact of the GED on annual earnings from the federal Social Security earnings file. Exploiting interstate variation in GED passing standards that existed across states in 1990 as an identification strategy, their difference-in-differences estimates place the impact of the GED on annual earnings at around 15 percent. What are the potential explanations that could reconcile these different results?

A first explanation for the different findings is that the natural experiment-based estimates in this paper are biased downward. As discussed earlier, while the passing standard change is surely exogenous to Texas, selection into the comparison group may not be, and under certain conditions discussed above, estimates based on the natural experiment may mis-estimate the causal impact of the GED on earnings. We conducted an exhaustive set of sensitivity analyses to examine this issue and none are supportive of a scenario whereby the 1997 affected score is systematically different from the 1995

\footnotetext{
${ }^{17}$ In analysis not shown here we examined results for white, 16-21 year olds, the exact group used in Tyler, Murnane, and Willett (2000). Estimates based on this more refined sample also show no evidence of a GED
} 
affected score group. Nonetheless, the differing sample sizes between these two groups evidenced in Table 2 is less than comforting, especially since the other groups exhibit sample size stability over this period. Given that the comparability of the treatment and comparison groups is ultimately an untestable question, we now turn to a reconciliation of results under an assumption that our natural experiment results in this paper are correct.

First, it could be the case that the research design employed by Tyler et al (2000) failed to adequately control for endogenous GED passing standard policies across states in a way that lead to an upward bias in their estimates. This potential criticism is tempered by the exhaustive set of sensitivity analyses conducted in that paper. Similar to the sensitivity analyses conducted in this current paper (including an examination of pretreatment earnings between the treatment and comparison groups), Tyler et al found consistent support for the validity of their natural experiment. Nevertheless, the mechanism behind the passing standard change that occurred in Texas is more transparent than the historical passing standard differences across states used by Tyler et al (2004), and given that, some might be more inclined to believe that the earlier estimates are biased upward and the natural experiment estimates in this paper are relatively unbiased.

A second explanation has to do with the different samples used in Tyler, Murnane, and Willett (2000) and in this paper. Estimates in Tyler, Murnane, and Willett are based on a pooled sample of males and females, and their estimated GED effect is a weighted average of the effect for males and the effect for females. Meanwhile, our estimates are based on a sample containing only males. A scenario where there are

effect on earnings. 
heterogeneous signaling effects of the GED by gender with positive effects for females and small or no effects for males would explain the differences between our results and those of Tyler, Murnane, and Willett (2000). Support for this possibility is found in Texas data similar to that used in this paper. Preliminary work we have done with samples of females from the Texas Schools Micro Data Panel indicate positive and statistically significant GED effects based on natural experimental specifications similar to those used for males in this paper. Exploring the extent to which heterogeneous returns by gender can reconcile the different results across papers is an important area for future research.

A third explanation concerns the signaling interpretation of the natural experiment estimates. As stated earlier, since the treatment and comparison groups are balanced on both the motivation to attempt the GED exams and on the GED test scores, what is being estimated is not the total impact of the GED, but rather the signaling value of this education credential. Prior to 1997, Texas, along with only three other states, had for many years the lowest passing standard allowable in the GED program. ${ }^{18}$ It could be that with such a low passing standard, the GED is a relatively useless signal of productivity to Texas employers. Evidence that supports this interpretation comes from regression discontinuity estimates of the impact of the GED using data from Florida (Tyler 2004). In the Florida study examinees whose GED test scores placed them just a few points on either side of the passing standard were compared. Because they were so close in score, it is reasonable to interpret the results as primarily estimates of the signaling value of the GED in Florida. The estimated impact of the GED from this regression discontinuity design was about a 20 percent increase in earnings, very similar to the Tyler et al (2000)

\footnotetext{
${ }^{18}$ The other states that had a similarly low passing standard pre-1997 were Louisiana, Mississippi, and Nebraska.
} 
results using national data. At the time of this study, Florida had the highest GED passing standard in the nation, except for Wisconsin and New Jersey. Thus, a possible inference is that having a high GED passing standard, as in Florida, results in a separating equilibrium that provides a meaningful signal to employers about the productivity of those possessing the signal. Meanwhile, if the passing standard is too low, such as might have been the case in Texas prior to 1997 , the mean productivity of GED holders will not be sufficiently different from that of uncredentialed dropouts resulting in a credential that conveys no useful information to employers.

The regression discontinuity estimates in this paper lend some support to this interpretation of how results across the studies can be reconciled. As discussed earlier, our regression discontinuity results based on the 1997 sample show a statistically significant fifth year signaling effect of about an eight percent increase in quarterly earnings. This compares to the 20 percent effect Tyler (2005) measured in Florida over roughly the same period and using the same regression discontinuity design.

Furthermore, our regression discontinuity results using the sample of 1995 test takers fail to find evidence of a positive pre-passing standard hike GED signaling effect. However, these results should be used with caution since the necessary sample restriction used to identify a discontinuity yields a small, possibly non-representative, subsample of test takers. These three sets of estimates, in combination with our natural experiment estimates, are consistent with a situation where:

1. the GED is a relatively strong signal of productivity in Florida because for many years this state had one of the highest GED passing standards, 
2. the GED in Texas was for many years a very weak signal of productivity because of the low passing standard, and

3. while still not as valuable as in Florida, the GED signal in Texas in 2001 (the year in which fifth-year earnings for 1997 testers were measured) was growing in reliability, and hence value, as the GED pool became increasingly populated with individuals who had passed under the higher standard and as employers adjusted to this fact.

To the extent that this explanation is the correct one for our results, they suggest that policy makers should think carefully about the role that passing cutoffs on high stakes tests play in determining the composition of the differing pools of "passers" and "failers," and how the composition of these pools affects the distribution of earnings. This is a lesson that others, including Betts and Costrell (2001), have effectively illustrated. If one goal of the GED program is to allow more motivated and skilled dropouts to distinguish themselves to employers, then the hike in passing standards mandated in 1997 may well have been one of the most important decisions the American Council on Education has made in recent years.

\section{Why obtain a GED if no effect on earnings?}

If the estimates in this paper represent the causal impact of the GED on earnings, the question raised is why would dropouts continue to acquire this credential if there is no economic benefit? There are several potential and non-mutually exclusive answers to this question. We first note that to the extent that we are only estimating the signaling value of the credential, we may be underestimating the total potential impact on earnings, 
composed of the returns to the signaling value and the returns to human capital component of the credential. Putting that caveat aside, however, one explanation is that there are non-economic benefits that dropouts derive from acquiring a GED. Anecdotally, GED preparation providers report that many of the "graduates" of their programs report that studying for and acquiring a GED is the first thing that they have accomplished on their own, and they proudly bring family to GED graduation ceremonies. Thus, feelings of pride and accomplishment could bring dropouts to the GED program even if there were no economic payoffs to the credential.

A second explanation for why we might see dropouts pursuing the credential is that at least in terms of direct costs, it is a relatively cheap credential. Direct costs for taking the GED exams can be as low as $\$ 35$ and even free in some cases. Also, GED preparation classes are often subsidized by the government and therefore of very low cost to participants. Furthermore, if the dropout attempting to obtain a GED is unemployed or out of the labor force, then there are no opportunity costs from lost employment to participate in GED preparation classes. Less clear are the psychic costs dropouts with a history of poor academic performance incur as they sit in GED preparation classes and subsequently take examinations that take up to seven and three-quarters hours. Nevertheless, government subsidization of GED preparation courses appears to make for very low direct costs associated with this credential.

\section{Conclusions}

Each year some three-quarters of a million individuals in this nation take the GED exams in hopes of passing and acquiring their GED certificate. Our results suggest that 
the signaling returns to this credential for male dropouts in Texas are substantially less than what has been found in other settings, since we find essentially no returns to the GED signal in Texas. One reason for this may be that the low GED passing threshold that existed in Texas for so long resulted in a credential that conveyed little information to employers. This explanation is supported by regression discontinuity results in this paper in comparison with results based on a similar regression discontinuity design using Florida data, a state with a historically high GED passing standard.

This paper has attempted to use a natural experiment in Texas to provide unbiased estimates of the return to the GED credential. The nature of the experiment provide us with estimates of the signaling value of the credential, net of any human capital effects that studying for the GED might generate. While it is important and valuable to understand the causal effects of programs such as the GED, some perspective is in order here. To provide this perspective, we ask the following question: what if the "total" GED effect (human capital plus signaling) was reasonably well estimated by the raw differences between GED examinees who passed the exams and GED examinees who failed? Based on Figure 2, this difference in Texas (which is similar to what one would see in Florida from Tyler's earlier work) is about a 25 percent return. By any measure, this is a large economic "return." Even so, in our Texas data this translates into annual earnings of only about $\$ 12,000$, instead of $\$ 10,000$, five years after the GED attempt. Thus, our examination of the GED credential in Texas mirrors other research on this credential in yet another important way. Namely, even if one thought that the total return to a GED was on the order of 25 percent, obtaining the GED as a "terminal" education credential is no route out of poverty. This suggests that the direction of further GED 
research should be in the areas of (1) how effective is this credential as an alternative route to postsecondary education and (2) does the very presence of the GED program provide some inducement to leave school for students who are on the margin of dropping out. 


\section{References}

Baldwin, Janet. 1990. GED Candidates: A Decade of Change. Washington, D.C.: GED Testing Service of the American Council on Education, 1.

Betts, Julian R. and Costrell, Robert M. "Incentives and Equity under Standards-Based Reform," D. Ravitch, Brookings Papers on Educational Policy 2001. Washington, D.C.: The Brookings Institution, 2001, 9-74.

Cameron, Stephen V. and James J. Heckman. 1993. "The Nonequivalence of High School Equivalents." Journal of Labor Economics, 11, no. 1, 1-47.

Heckman, James J., Jingjing Hsse, and Yona Rubinstein. 2000. "The GED is a "Mixed Signal": The Effect of Cognitive and non-Cognitive Skills on Human Capital and Labor Market Outcomes." Unpublished University of Chicago manuscript.

Heckman, James J. and Yona Rubinstein. 2001. “The Importance of Noncognitive Skills: Lessons from the GED Testing Program." American Economic Review 91, no. 2, 145-49.

Murnane, Richard J., John B. Willett, and Katherine P. Boudett. 1995. "Do High School Dropouts Benefit from Obtaining a GED?" Educational Evaluation and Policy Analysis 17, no. 2, 133-147.

1997. "Does Acquisition of a GED Lead to More Training, Post-secondary Education, and Military Service for School Dropouts?" Industrial and Labor Relations Review 51, no. 1, 100-116.

Murnane, Richard J., John B. Willett, and Kathryn Parker Boudett. 1999. "Do Male Dropouts Benefit from Obtaining a GED, Postsecondary Education, and Training?" Evaluation Review 22, no. 5, 475-502.

Murnane, Richard J., John B. Willett, and John H. Tyler. 2000. "Who Benefits from a GED? Evidence from High School and Beyond." The Review of Economics and Statistics 82, no. 1, 23-37.

Spence, Michael. 1973. "Job Market Signaling." Quarterly Journal of Economics 87, no. 3, 355-374.

Tyler, John H. 2004. "What is the Value of the GED to Dropouts Who Pursue the Credential?" Industrial and Labor Relations Review, 57, No.4, 587-598.

Tyler, John H., Richard J. Murnane, and John B. Willett. 2000. "Estimating the Labor Market Signaling Value of the GED." Quarterly Journal of Economics CXV, no. 2, 431468. 
Table 1.

Summary Statistics by Year of Attempting the GED.

\begin{tabular}{|c|c|c|c|}
\hline & \multicolumn{2}{|c|}{ Year Attempted the GED } & \multirow{2}{*}{$\begin{array}{r}\text { Difference } \\
(1997-1995)\end{array}$} \\
\hline & 1995 & 1997 & \\
\hline Highest Grade Attained & 9.82 & 9.75 & $-0.06^{*}$ \\
\hline Age when took GED & 21.41 & 21.31 & $-0.10^{*}$ \\
\hline Non-Hispanic White & $42.0 \%$ & $42.6 \%$ & $0.5 \%$ \\
\hline Hispanic & $39.1 \%$ & $38.9 \%$ & $-0.1 \%$ \\
\hline African American & $14.1 \%$ & $13.0 \%$ & $-1.1 \% *$ \\
\hline Asian & $1.2 \%$ & $1.3 \%$ & $0.1 \%$ \\
\hline All Other & $3.7 \%$ & $4.3 \%$ & $0.6 \% *$ \\
\hline GED in Spanish & $3.9 \%$ & $5.0 \%$ & $1.1 \% *$ \\
\hline \multicolumn{4}{|l|}{ Test Scores: } \\
\hline Writing Skills & 45.45 & 45.70 & $0.25^{*}$ \\
\hline Social Studies & 48.60 & 49.77 & $1.17^{*}$ \\
\hline Science & 49.47 & 49.94 & $0.47^{*}$ \\
\hline Interpreting Lit. \& the Arts & 47.69 & 48.61 & $0.92^{*}$ \\
\hline Mathematics. & 47.38 & 48.42 & $1.04^{*}$ \\
\hline Average Score & 47.72 & 48.49 & $0.77^{*}$ \\
\hline Min Score & 42.98 & 43.66 & $0.68^{*}$ \\
\hline Passed the GED & $78.7 \%$ & $68.7 \%$ & $-10.0 \% *$ \\
\hline \multicolumn{4}{|c|}{ Pre-Test Taking Employment and Earnings: } \\
\hline $\begin{array}{l}\text { Experience (Quarters) } \\
\text { Average Quarterly Earnings }\end{array}$ & 7.56 & 7.59 & 0.03 \\
\hline 6 Years Prior to Attempting the GED & $\$ 528$ & $\$ 490$ & $-\$ 39^{*}$ \\
\hline 5 Years Prior to Attempting the GED & $\$ 623$ & $\$ 568$ & $-\$ 55^{*}$ \\
\hline 4 Years Prior to Attempting the GED & $\$ 697$ & $\$ 681$ & $-\$ 16$ \\
\hline 3 Years Prior to Attempting the GED & $\$ 824$ & $\$ 852$ & $\$ 28$ \\
\hline 2 Years Prior to Attempting the GED & $\$ 1,025$ & $\$ 1,050$ & $\$ 25$ \\
\hline 1 Year Prior to Attempting the GED & $\$ 1,214$ & $\$ 1,241$ & $\$ 27$ \\
\hline Number of Individuals & 28,449 & 24,734 & \\
\hline
\end{tabular}

Note: * indicates differerence is statistically significantly different from zero at a $5 \%$ significance level or less. 
Table 2.

Summary Statistics by GED Outcome Group.

\begin{tabular}{|c|c|c|c|c|c|c|}
\hline & \multirow{2}{*}{\multicolumn{2}{|c|}{ All Fail }} & \multicolumn{2}{|c|}{$\begin{array}{l}\text { GED Outcome Group } \\
\text { Affected Score Group }\end{array}$} & \multirow{2}{*}{\multicolumn{2}{|c|}{ All Pass }} \\
\hline & & & Treatment & Comparison & & \\
\hline & $\underline{1995}$ & 1997 & Passed 1995 & Failed 1997 & 1995 & 1997 \\
\hline Highest Grade Attained & $9.62^{*}$ & $9.52^{*}$ & 9.67 & 9.59 & $9.94^{*}$ & $9.85^{*}$ \\
\hline Age when took GED & $22.57^{*}$ & $22.16^{*}$ & $21.22^{*}$ & $21.53^{*}$ & 21.03 & 20.97 \\
\hline Non-Hispanic White & $27.1 \%$ & $27.6 \%$ & $31.9 \%$ & $30.7 \%$ & $51.1 \% *$ & $49.3 \%$ * \\
\hline Hispanic & $46.4 \%$ & $45.3 \%$ & $44.7 \%$ & $42.7 \%$ & $34.4 \%{ }^{*}$ & $36.2 \%{ }^{*}$ \\
\hline African American & $20.5 \%$ & $20.5 \%$ & $18.5 \%$ & $20.4 \%$ & $10.2 \%$ & $9.6 \%$ \\
\hline Asian & $1.3 \%$ & $1.6 \%$ & $1.3 \%$ & $1.4 \%$ & $1.2 \%$ & $1.2 \%$ \\
\hline All Other & $4.7 \%$ & $5.1 \%$ & $3.9 \%$ & $4.8 \%$ & $3.2 \% *$ & $4.0 \% *$ \\
\hline Took the GED in Spanish & $2.5 \%$ & $2.2 \%$ & $1.8 \% *$ & $2.7 \% *$ & $5.1 \% *$ & $6.2 \% *$ \\
\hline \multicolumn{7}{|l|}{ Test Scores: } \\
\hline Writing Skills & 39.35 & 39.48 & $42.69^{*}$ & $42.23^{*}$ & $48.72^{*}$ & $48.33^{*}$ \\
\hline Social Studies & $40.95^{*}$ & $41.42^{*}$ & 44.59 & 44.63 & $52.88^{*}$ & $53.35^{*}$ \\
\hline Science & 41.83 & 41.85 & 45.42 & 45.25 & $53.75^{\star}$ & $53.39^{*}$ \\
\hline Interpreting Lit. \& the Arts & $40.38^{*}$ & $41.03^{*}$ & 44.02 & 44.05 & 51.73 & 51.86 \\
\hline Mathematics. & 40.20 & 40.40 & 43.87 & 44.11 & $51.30^{\star}$ & $51.80^{*}$ \\
\hline Average Score & $40.54^{*}$ & $40.84^{*}$ & 44.12 & 44.06 & 51.67 & 51.75 \\
\hline Min Score & $36.86^{*}$ & $37.16^{\star}$ & 39.88 & 40.13 & 46.36 & 46.41 \\
\hline \multicolumn{7}{|l|}{ Pre-Test Taking: } \\
\hline $\begin{array}{l}\text { Experience (Quarters) } \\
\text { Average Quarterly Earnings }\end{array}$ & 7.82 & 7.60 & $7.19^{*}$ & $7.85^{*}$ & 7.59 & 7.56 \\
\hline 6 Years Prior to Attempting the GED & $\$ 656^{*}$ & $\$ 549^{*}$ & $\$ 451$ & $\$ 464$ & $\$ 506^{*}$ & $\$ 470^{*}$ \\
\hline 5 Years Prior to Attempting the GED & $\$ 763^{*}$ & $\$ 609^{*}$ & $\$ 528$ & $\$ 564$ & $\$ 602^{*}$ & $\$ 553^{*}$ \\
\hline 4 Years Prior to Attempting the GED & $\$ 815^{*}$ & $\$ 709^{*}$ & $\$ 601$ & $\$ 692$ & $\$ 684$ & $\$ 670$ \\
\hline 3 Years Prior to Attempting the GED & $\$ 918$ & $\$ 859$ & $\$ 727^{*}$ & $\$ 866^{*}$ & $\$ 820$ & $\$ 848$ \\
\hline 2 Years Prior to Attempting the GED & $\$ 1,104^{*}$ & $\$ 1,004^{*}$ & $\$ 914^{*}$ & $\$ 1,072^{*}$ & $\$ 1,032$ & $\$ 1,065$ \\
\hline 1 Year Prior to Attempting the GED & $\$ 1,229^{*}$ & $\$ 1,152^{*}$ & $\$ 1,089^{*}$ & $\$ 1,247^{*}$ & $\$ 1,251$ & $\$ 1,274$ \\
\hline Number of Individuals & 6,311 & 6,303 & 5,590 & 1,532 & 16,548 & 16,899 \\
\hline
\end{tabular}

Note: * indicates whether 1997-1995 within GED outcome group differerence is statistically significantly

different from zero at a $5 \%$ significance level or less. 
Table 3.

Estimated Quarterly Earnings based on Specifications (1), (2) and (3).

\begin{tabular}{|c|c|c|c|c|c|}
\hline Specification & $\begin{array}{c}\text { Model } 1 \\
\text { Simple OLS }\end{array}$ & $\begin{array}{c}\text { Model } 2 \\
\text { Simple OLS }\end{array}$ & $\begin{array}{c}\text { Model } 3 \\
\text { Simple OLS }\end{array}$ & $\begin{array}{c}\text { Model } 4 \\
\text { Fixed Effect }\end{array}$ & $\begin{array}{c}\text { Model } 5 \\
\text { Discontinuity }\end{array}$ \\
\hline Intercept & $\begin{array}{c}-6441.09 \\
(27.85)\end{array}$ & $\begin{array}{c}1178.41 \\
(6.04)\end{array}$ & $\begin{array}{l}-60.35 \\
(0.18)\end{array}$ & $\begin{array}{c}-3857.60 \\
(41.21)\end{array}$ & $\begin{array}{c}2526.22 \\
(3.69)\end{array}$ \\
\hline GED Holder & $\begin{array}{l}60.26 \\
(2.74)\end{array}$ & $\begin{array}{l}-76.12 \\
(4.72)\end{array}$ & $\begin{array}{c}-129.93 \\
(5.53)\end{array}$ & $\begin{array}{l}222.04 \\
(26.08)\end{array}$ & $\begin{array}{c}-100.16 \\
(1.50)\end{array}$ \\
\hline Years Since Took the GED: & & & & & \\
\hline 2nd Year*GED Holder & $\begin{array}{l}124.67 \\
(8.25)\end{array}$ & $\begin{array}{c}126.26 \\
(8.36)\end{array}$ & $\begin{array}{c}126.28 \\
(8.36)\end{array}$ & $\begin{array}{l}-18.99 \\
(1.51)\end{array}$ & $\begin{array}{c}168.10 \\
(4.67)\end{array}$ \\
\hline 3rd Year*GED Holder & $\begin{array}{l}213.10 \\
(10.38)\end{array}$ & $\begin{array}{l}214.72 \\
(10.46)\end{array}$ & $\begin{array}{l}214.67 \\
(10.46)\end{array}$ & $\begin{array}{l}60.94 \\
(4.87)\end{array}$ & $\begin{array}{l}218.02 \\
(4.54)\end{array}$ \\
\hline 4th Year*GED Holder & $\begin{array}{l}296.66 \\
(12.25)\end{array}$ & $\begin{array}{l}298.39 \\
(12.33)\end{array}$ & $\begin{array}{l}298.28 \\
(12.32)\end{array}$ & $\begin{array}{l}141.31 \\
(11.27)\end{array}$ & $\begin{array}{c}250.49 \\
(4.43)\end{array}$ \\
\hline 5th Year*GED Holder & $\begin{array}{l}363.00 \\
(13.20)\end{array}$ & $\begin{array}{l}364.28 \\
(13.27)\end{array}$ & $\begin{array}{l}364.44 \\
(13.27)\end{array}$ & $\begin{array}{l}204.37 \\
(16.30)\end{array}$ & $\begin{array}{c}289.47 \\
(4.56)\end{array}$ \\
\hline 2nd Year & $\begin{array}{l}38.52 \\
(2.09)\end{array}$ & $\begin{array}{l}119.79 \\
(7.13)\end{array}$ & $\begin{array}{c}120.44 \\
(7.17)\end{array}$ & $\begin{array}{l}157.74 \\
(12.84)\end{array}$ & $\begin{array}{l}-58.88 \\
(1.36)\end{array}$ \\
\hline 3rd Year & $\begin{array}{l}74.83 \\
(2.44)\end{array}$ & $\begin{array}{c}233.73 \\
(8.69)\end{array}$ & $\begin{array}{c}234.86 \\
(8.74)\end{array}$ & $\begin{array}{l}147.59 \\
(10.03)\end{array}$ & $\begin{array}{l}11.26 \\
(0.15)\end{array}$ \\
\hline 4th Year & $\begin{array}{l}89.66 \\
(2.07)\end{array}$ & $\begin{array}{c}324.53 \\
(8.77)\end{array}$ & $\begin{array}{c}326.20 \\
(8.82)\end{array}$ & $\begin{array}{l}131.68 \\
(7.23)\end{array}$ & $\begin{array}{l}79.00 \\
(0.74)\end{array}$ \\
\hline 5th Year & $\begin{array}{l}142.88 \\
(2.57)\end{array}$ & $\begin{array}{c}457.26 \\
(9.77)\end{array}$ & $\begin{array}{l}458.27 \\
(9.80)\end{array}$ & $\begin{array}{c}159.24 \\
(7.47)\end{array}$ & $\begin{array}{l}186.42 \\
(1.31)\end{array}$ \\
\hline $\begin{array}{l}\text { Attempted GED in } 1995 \\
\text { Other Control Variables: }\end{array}$ & $\begin{array}{l}-49.53 \\
(2.27)\end{array}$ & $\begin{array}{l}15.67 \\
(0.89)\end{array}$ & $\begin{array}{l}26.03 \\
(1.45)\end{array}$ & & \\
\hline Highest Grade Attained & $\begin{array}{l}139.92 \\
(17.73)\end{array}$ & $\begin{array}{c}72.83 \\
(11.84)\end{array}$ & $\begin{array}{c}69.96 \\
(11.30)\end{array}$ & & $\begin{array}{l}61.85 \\
(4.82)\end{array}$ \\
\hline Age & $\begin{array}{l}303.49 \\
(16.46)\end{array}$ & $\begin{array}{l}218.43 \\
(12.47)\end{array}$ & $\begin{array}{l}219.15 \\
(12.51)\end{array}$ & $\begin{array}{l}373.75 \\
(71.88)\end{array}$ & $\begin{array}{l}174.27 \\
(3.88)\end{array}$ \\
\hline Age Squared/100 & $\begin{array}{c}-348.15 \\
(9.96)\end{array}$ & $\begin{array}{c}-344.34 \\
(10.51)\end{array}$ & $\begin{array}{l}-345.55 \\
(10.55)\end{array}$ & $\begin{array}{l}-536.78 \\
(71.62)\end{array}$ & $\begin{array}{c}-274.93 \\
(3.47)\end{array}$ \\
\hline Age when Took GED & $\begin{array}{l}167.27 \\
(6.48)\end{array}$ & $\begin{array}{c}-328.74 \\
(14.57)\end{array}$ & $\begin{array}{l}-324.08 \\
(14.39)\end{array}$ & & $\begin{array}{c}-259.85 \\
(4.90)\end{array}$ \\
\hline Age when Took GED^2/100 & $\begin{array}{c}-314.07 \\
(6.05)\end{array}$ & $\begin{array}{l}524.70 \\
(11.81)\end{array}$ & $\begin{array}{l}517.57 \\
(11.67)\end{array}$ & & $\begin{array}{l}404.31 \\
(4.02)\end{array}$ \\
\hline Hispanic & $\begin{array}{l}-29.96 \\
(1.23)\end{array}$ & $\begin{array}{l}90.83 \\
(4.65)\end{array}$ & $\begin{array}{l}97.78 \\
(4.91)\end{array}$ & & $\begin{array}{l}141.82 \\
(3.22)\end{array}$ \\
\hline African- American & $\begin{array}{c}-1273.55 \\
(43.83)\end{array}$ & $\begin{array}{l}-506.25 \\
(21.35)\end{array}$ & $\begin{array}{c}-473.20 \\
(19.45)\end{array}$ & & $\begin{array}{c}-472.56 \\
(9.20)\end{array}$ \\
\hline Asian & $\begin{array}{c}-324.31 \\
(3.12)\end{array}$ & $\begin{array}{l}151.14 \\
(1.68)\end{array}$ & $\begin{array}{l}82.74 \\
(0.92)\end{array}$ & & $\begin{array}{c}266.55 \\
(1.30)\end{array}$ \\
\hline Other Ethnicity & $\begin{array}{c}-399.84 \\
(7.25)\end{array}$ & $\begin{array}{l}-74.79 \\
(1.65)\end{array}$ & $\begin{array}{l}-64.62 \\
(1.43)\end{array}$ & & $\begin{array}{c}-13.69 \\
(0.13)\end{array}$ \\
\hline Took GED in Spanish & $\begin{array}{c}-380.71 \\
(5.89)\end{array}$ & $\begin{array}{l}64.38 \\
(1.27)\end{array}$ & $\begin{array}{l}54.86 \\
(1.04)\end{array}$ & & \\
\hline Continued... & & & & & \\
\hline
\end{tabular}




\begin{tabular}{|c|c|c|c|c|c|}
\hline Table 3, Continued & Model 1 & Model 2 & Model 3 & Model 4 & Model 5 \\
\hline \multicolumn{6}{|l|}{ GED Scores: } \\
\hline Writing Skills & & & $\begin{array}{c}0.18 \\
(0.01)\end{array}$ & & \\
\hline Writing Skills ${ }^{2}$ & & & $\begin{array}{l}-0.10 \\
(0.68)\end{array}$ & & \\
\hline Social Studies & & & $\begin{array}{l}-15.85 \\
(1.55)\end{array}$ & & \\
\hline Social Studies $^{2}$ & & & $\begin{array}{c}0.18 \\
(1.73)\end{array}$ & & \\
\hline Science & & & $\begin{array}{l}50.14 \\
(4.09)\end{array}$ & & \\
\hline Science $^{2}$ & & & $\begin{array}{l}-0.45 \\
(3.72)\end{array}$ & & \\
\hline Interpreting Lit. \& the Arts & & & $\begin{array}{l}-17.65 \\
(1.77)\end{array}$ & & \\
\hline Interpreting Lit. \& the Arts $^{2}$ & & & $\begin{array}{c}0.08 \\
(0.82)\end{array}$ & & \\
\hline Mathematics & & & $\begin{array}{l}31.67 \\
(2.97)\end{array}$ & & \\
\hline Mathematics $^{2}$ & & & $\begin{array}{l}-0.19 \\
(1.69)\end{array}$ & & \\
\hline Average & & & & & $\begin{array}{c}-22.88 \\
(2.06)\end{array}$ \\
\hline Time Fixed Effect Included & Yes & Yes & Yes & Yes & Yes \\
\hline Pre-Test Taking Experience & No & Yes & Yes & No & Yes \\
\hline Pre-Test Taking Earnings & No & Yes & Yes & No & Yes \\
\hline GED Test Scores & No & No & All Tests & No & Average \\
\hline Number of Observations & & $1,044,604$ & & $1,414,535$ & 200,583 \\
\hline Number of Individuals & & 52,251 & & 52,251 & 10,033 \\
\hline R-squared & 0.080 & 0.277 & 0.278 & 0.100 & 0.287 \\
\hline
\end{tabular}

Note: t-values based on robust standard errors are shown in parentheses. Furthermore, the standard errors are obtained assuming disturbances are independent across individuals but allows for dependence for individuals' repeated observations over time, i.e. within group/individual correlation of disturbance term. 
Table 4.

Estimated Quarterly Earnings Differences, GED Holders and Non-GED Holders, based on Results in Table 3.

\begin{tabular}{|c|c|c|c|c|c|}
\hline \multirow[b]{2}{*}{ Year Since Attempted the GED } & \multicolumn{5}{|c|}{ Estimated Earnings Difference: GED Holders - Non-GED Holders } \\
\hline & $\begin{array}{c}\text { Model } 1 \\
\text { Simple } \\
\text { OLS }\end{array}$ & $\begin{array}{c}\text { Model } 2 \\
\text { Simple } \\
\text { OLS }\end{array}$ & $\begin{array}{c}\text { Model } 3 \\
\text { Simple } \\
\text { OLS }\end{array}$ & $\begin{array}{c}\text { Model } 4 \\
\text { Fixed Effect }\end{array}$ & $\begin{array}{c}\text { Model } 5 \\
\text { Discontinuity }\end{array}$ \\
\hline First Year & $\begin{array}{c}60.26 \\
(21.96)\end{array}$ & $\begin{array}{l}-76.12 \\
(16.14)\end{array}$ & $\begin{array}{c}-129.93 \\
(23.49)\end{array}$ & $\begin{array}{c}222.04 \\
(8.51)\end{array}$ & $\begin{array}{c}-100.16 \\
(66.73)\end{array}$ \\
\hline Second Year & $\begin{array}{l}184.92 \\
(24.68)\end{array}$ & $\begin{array}{c}50.15 \\
(19.87)\end{array}$ & $\begin{array}{c}-3.65 \\
(26.44)\end{array}$ & $\begin{array}{l}203.05 \\
(11.76)\end{array}$ & $\begin{array}{c}67.94 \\
(72.41)\end{array}$ \\
\hline Third Year & $\begin{array}{l}273.35 \\
(27.66)\end{array}$ & $\begin{array}{l}138.60 \\
(23.33)\end{array}$ & $\begin{array}{c}84.74 \\
(29.21)\end{array}$ & $\begin{array}{l}282.98 \\
(11.81)\end{array}$ & $\begin{array}{l}117.86 \\
(78.43)\end{array}$ \\
\hline Fourth Year & $\begin{array}{l}356.91 \\
(30.27)\end{array}$ & $\begin{array}{l}222.27 \\
(26.19)\end{array}$ & $\begin{array}{l}168.36 \\
(31.53)\end{array}$ & $\begin{array}{l}363.35 \\
(11.81)\end{array}$ & $\begin{array}{l}150.32 \\
(83.66)\end{array}$ \\
\hline Fifth Year & $\begin{array}{l}423.26 \\
(32.76)\end{array}$ & $\begin{array}{l}288.16 \\
(28.97)\end{array}$ & $\begin{array}{l}234.51 \\
(33.89)\end{array}$ & $\begin{array}{l}426.41 \\
(11.84)\end{array}$ & $\begin{array}{l}189.30 \\
(88.82)\end{array}$ \\
\hline Test $\mathrm{H}_{0}$ :GED Effect $=0, P$-value. & & & & & \\
\hline First Year (t-test) & 0.006 & $<0.001$ & $<0.001$ & $<0.001$ & 0.133 \\
\hline Second Year (F-test) & $<0.001$ & 0.012 & 0.890 & $<0.001$ & 0.348 \\
\hline Third Year (F-test) & $<0.001$ & $<0.001$ & 0.004 & $<0.001$ & 0.133 \\
\hline Fourth Year (F-test) & $<0.001$ & $<0.001$ & $<0.001$ & $<0.001$ & 0.072 \\
\hline Fifth Year (F-test) & $<0.001$ & $<0.001$ & $<0.001$ & $<0.001$ & 0.033 \\
\hline Included Controls & & & & & \\
\hline$\overline{\text { Time Fixed Effect }}$ & Yes & Yes & Yes & Yes & Yes \\
\hline Age, Schooling, Ethnicity & Yes & Yes & Yes & Age & Yes \\
\hline Pre-Test Taking Experience & No & Yes & Yes & No & Yes \\
\hline Pre-Test Taking Earnings & No & Yes & Yes & No & Yes \\
\hline GED Test Scores & No & No & All Tests & No & Average \\
\hline Number of Observations & & $1,044,604$ & & $1,414,535$ & 200,583 \\
\hline Number of Individuals & & 52,251 & & 52,251 & 10,033 \\
\hline R-squared & 0.080 & 0.277 & 0.278 & 0.100 & 0.287 \\
\hline
\end{tabular}

Note: Standard errors are shown in parentheses. 
Table 5.

Estimated Quarterly Earnings based on Specification (4) - Natural Experiment.

\begin{tabular}{|c|c|c|c|c|c|c|}
\hline Variable & Model 1 & Model 2 & Model 3 & Model 4 & Model 5 & Model 6 \\
\hline \multicolumn{7}{|c|}{ GED Outcome and Years Since Took the GED } \\
\hline Constant & $\begin{array}{c}1756.45 \\
(62.40)\end{array}$ & $\begin{array}{l}972.48 \\
(14.94)\end{array}$ & $\begin{array}{c}-6839.01 \\
(28.69)\end{array}$ & $\begin{array}{c}2022.34 \\
(8.79)\end{array}$ & $\begin{array}{c}-378.25 \\
(1.84)\end{array}$ & $\begin{array}{c}690.53 \\
(3.48)\end{array}$ \\
\hline 2nd Year & $\begin{array}{l}289.86 \\
(15.41)\end{array}$ & $\begin{array}{c}114.37 \\
(4.14)\end{array}$ & $\begin{array}{l}62.11 \\
(2.40)\end{array}$ & $\begin{array}{l}99.12 \\
(4.01)\end{array}$ & $\begin{array}{c}103.06 \\
(4.31)\end{array}$ & $\begin{array}{c}107.97 \\
(4.53)\end{array}$ \\
\hline 3rd Year & $\begin{array}{l}508.75 \\
(19.80)\end{array}$ & $\begin{array}{c}232.83 \\
(4.77)\end{array}$ & $\begin{array}{l}132.31 \\
(2.96)\end{array}$ & $\begin{array}{c}205.94 \\
(4.90)\end{array}$ & $\begin{array}{r}214.21 \\
(5.34)\end{array}$ & $\begin{array}{c}223.94 \\
(5.60)\end{array}$ \\
\hline 4th Year & $\begin{array}{l}613.98 \\
(21.18)\end{array}$ & $\begin{array}{c}279.85 \\
(4.01)\end{array}$ & $\begin{array}{c}133.78 \\
(2.11)\end{array}$ & $\begin{array}{c}237.45 \\
(4.04)\end{array}$ & $\begin{array}{c}250.63 \\
(4.49)\end{array}$ & $\begin{array}{c}262.66 \\
(4.72)\end{array}$ \\
\hline 5th Year & $\begin{array}{l}589.43 \\
(18.02)\end{array}$ & $\begin{array}{c}316.44 \\
(3.36)\end{array}$ & $\begin{array}{c}127.86 \\
(1.50)\end{array}$ & $\begin{array}{c}257.27 \\
(3.26)\end{array}$ & $\begin{array}{c}276.03 \\
(3.69)\end{array}$ & $\begin{array}{c}288.84 \\
(3.88)\end{array}$ \\
\hline Before & $\begin{array}{l}-39.40 \\
(0.97)\end{array}$ & $\begin{array}{c}477.39 \\
(8.29)\end{array}$ & $\begin{array}{c}244.90 \\
(4.02)\end{array}$ & $\begin{array}{c}368.13 \\
(6.95)\end{array}$ & $\begin{array}{c}311.09 \\
(6.77)\end{array}$ & $\begin{array}{c}338.65 \\
(7.38)\end{array}$ \\
\hline 2nd Year* Before & $\begin{array}{l}-70.36 \\
(2.67)\end{array}$ & $\begin{array}{l}-93.94 \\
(3.17)\end{array}$ & $\begin{array}{l}-83.77 \\
(2.85)\end{array}$ & $\begin{array}{l}-75.84 \\
(2.62)\end{array}$ & $\begin{array}{r}-75.40 \\
(2.65)\end{array}$ & $\begin{array}{l}-72.35 \\
(2.54)\end{array}$ \\
\hline 3rd Year* Before & $\begin{array}{l}-23.54 \\
(0.67)\end{array}$ & $\begin{array}{c}-254.81 \\
(6.13)\end{array}$ & $\begin{array}{c}-235.16 \\
(5.71)\end{array}$ & $\begin{array}{c}-224.44 \\
(5.52)\end{array}$ & $\begin{array}{c}-223.33 \\
(5.56)\end{array}$ & $\begin{array}{c}-219.21 \\
(5.45)\end{array}$ \\
\hline 4th Year* Before & $\begin{array}{c}133.43 \\
(3.22)\end{array}$ & $\begin{array}{c}-223.58 \\
(4.28)\end{array}$ & $\begin{array}{c}-193.64 \\
(3.75)\end{array}$ & $\begin{array}{c}-177.34 \\
(3.51)\end{array}$ & $\begin{array}{c}-175.60 \\
(3.53)\end{array}$ & $\begin{array}{c}-169.28 \\
(3.40)\end{array}$ \\
\hline 5th Year* Before & $\begin{array}{c}337.67 \\
(7.20)\end{array}$ & $\begin{array}{c}-178.85 \\
(2.69)\end{array}$ & $\begin{array}{c}-137.70 \\
(2.11)\end{array}$ & $\begin{array}{c}-111.84 \\
(1.77)\end{array}$ & $\begin{array}{c}-109.75 \\
(1.78)\end{array}$ & $\begin{array}{l}-99.81 \\
(1.62)\end{array}$ \\
\hline Affected Score Group (ASG) & $\begin{array}{c}216.98 \\
(3.36)\end{array}$ & $\begin{array}{c}209.84 \\
(3.25)\end{array}$ & $\begin{array}{c}271.02 \\
(4.49)\end{array}$ & $\begin{array}{c}188.17 \\
(3.62)\end{array}$ & $\begin{array}{c}144.75 \\
(3.12)\end{array}$ & $\begin{array}{c}131.08 \\
(2.85)\end{array}$ \\
\hline 2nd Year*ASG & $\begin{array}{l}-75.11 \\
(1.64)\end{array}$ & $\begin{array}{l}-68.82 \\
(1.51)\end{array}$ & $\begin{array}{l}-73.19 \\
(1.60)\end{array}$ & $\begin{array}{l}-72.63 \\
(1.59)\end{array}$ & $\begin{array}{l}-72.95 \\
(1.60)\end{array}$ & $\begin{array}{l}-72.86 \\
(1.60)\end{array}$ \\
\hline 3rd Year*ASG & $\begin{array}{c}5.53 \\
(0.09)\end{array}$ & $\begin{array}{l}10.29 \\
(0.18)\end{array}$ & $\begin{array}{c}1.24 \\
(0.02)\end{array}$ & $\begin{array}{c}2.54 \\
(0.04)\end{array}$ & $\begin{array}{c}1.87 \\
(0.03)\end{array}$ & $\begin{array}{c}2.07 \\
(0.04)\end{array}$ \\
\hline 4th Year*ASG & $\begin{array}{l}102.56 \\
(1.51)\end{array}$ & $\begin{array}{c}109.42 \\
(1.62)\end{array}$ & $\begin{array}{l}96.27 \\
(1.42)\end{array}$ & $\begin{array}{l}97.34 \\
(1.44)\end{array}$ & $\begin{array}{l}96.28 \\
(1.42)\end{array}$ & $\begin{array}{l}96.52 \\
(1.43)\end{array}$ \\
\hline 5th Year*ASG & $\begin{array}{c}105.87 \\
(1.43)\end{array}$ & $\begin{array}{c}114.92 \\
(1.56)\end{array}$ & $\begin{array}{l}97.56 \\
(1.32)\end{array}$ & $\begin{array}{l}99.01 \\
(1.34)\end{array}$ & $\begin{array}{l}97.48 \\
(1.32)\end{array}$ & $\begin{array}{l}97.81 \\
(1.33)\end{array}$ \\
\hline Before*ASG & $\begin{array}{c}-334.41 \\
(4.40)\end{array}$ & $\begin{array}{c}-330.43 \\
(4.35)\end{array}$ & $\begin{array}{c}-259.08 \\
(3.65)\end{array}$ & $\begin{array}{c}-182.20 \\
(2.98)\end{array}$ & $\begin{array}{c}-149.65 \\
(2.81)\end{array}$ & $\begin{array}{c}-152.16 \\
(2.87)\end{array}$ \\
\hline 2nd Year*Before*ASG & $\begin{array}{c}174.05 \\
(3.27)\end{array}$ & $\begin{array}{c}168.58 \\
(3.17)\end{array}$ & $\begin{array}{c}163.49 \\
(3.08)\end{array}$ & $\begin{array}{c}163.78 \\
(3.08)\end{array}$ & $\begin{array}{l}163.13 \\
(3.07)\end{array}$ & $\begin{array}{c}163.28 \\
(3.07)\end{array}$ \\
\hline 3rd Year*Before*ASG & $\begin{array}{c}159.92 \\
(2.31)\end{array}$ & $\begin{array}{c}153.05 \\
(2.22)\end{array}$ & $\begin{array}{l}143.14 \\
(2.07)\end{array}$ & $\begin{array}{c}143.08 \\
(2.07)\end{array}$ & $\begin{array}{c}142.00 \\
(2.06)\end{array}$ & $\begin{array}{c}142.22 \\
(2.06)\end{array}$ \\
\hline 4th Year*Before*ASG & $\begin{array}{c}105.38 \\
(1.30)\end{array}$ & $\begin{array}{l}101.04 \\
(1.25)\end{array}$ & $\begin{array}{l}85.81 \\
(1.06)\end{array}$ & $\begin{array}{l}86.95 \\
(1.08)\end{array}$ & $\begin{array}{l}85.22 \\
(1.05)\end{array}$ & $\begin{array}{l}85.66 \\
(1.06)\end{array}$ \\
\hline 5th Year*Before ${ }^{*}$ ASG & $\begin{array}{c}161.61 \\
(1.80)\end{array}$ & $\begin{array}{l}153.95 \\
(1.72)\end{array}$ & $\begin{array}{l}133.35 \\
(1.49)\end{array}$ & $\begin{array}{c}134.84 \\
(1.51)\end{array}$ & $\begin{array}{c}132.81 \\
(1.48)\end{array}$ & $\begin{array}{c}133.37 \\
(1.49)\end{array}$ \\
\hline All Passing Group & $\begin{array}{l}116.39 \\
(3.49)\end{array}$ & $\begin{array}{l}112.26 \\
(3.36)\end{array}$ & $\begin{array}{l}106.30 \\
(3.31)\end{array}$ & $\begin{array}{c}5.56 \\
(0.20)\end{array}$ & $\begin{array}{l}-66.48 \\
(2.80)\end{array}$ & $\begin{array}{l}-78.90 \\
(3.33)\end{array}$ \\
\hline Continued... & & & & & & \\
\hline
\end{tabular}




\begin{tabular}{|c|c|c|c|c|c|c|}
\hline Table 5, Continued & Model 1 & Model 2 & Model 3 & Model 4 & Model 5 & Model 6 \\
\hline 2nd Year*All Passing & $\begin{array}{c}147.01 \\
(6.41)\end{array}$ & $\begin{array}{c}150.64 \\
(6.58)\end{array}$ & $\begin{array}{c}142.02 \\
(6.20)\end{array}$ & $\begin{array}{c}142.74 \\
(6.23)\end{array}$ & $\begin{array}{c}141.93 \\
(6.20)\end{array}$ & $\begin{array}{c}142.14 \\
(6.21)\end{array}$ \\
\hline 3rd Year*All Passing & $\begin{array}{c}268.79 \\
(8.50)\end{array}$ & $\begin{array}{c}271.54 \\
(8.59)\end{array}$ & $\begin{array}{c}254.34 \\
(8.04)\end{array}$ & $\begin{array}{c}255.75 \\
(8.09)\end{array}$ & $\begin{array}{c}254.13 \\
(8.04)\end{array}$ & $\begin{array}{c}254.56 \\
(8.05)\end{array}$ \\
\hline 4th Year*All Passing & $\begin{array}{l}382.04 \\
(10.58)\end{array}$ & $\begin{array}{l}386.00 \\
(10.70)\end{array}$ & $\begin{array}{c}360.17 \\
(9.97)\end{array}$ & $\begin{array}{l}362.03 \\
(10.02)\end{array}$ & $\begin{array}{c}359.69 \\
(9.96)\end{array}$ & $\begin{array}{c}360.28 \\
(9.98)\end{array}$ \\
\hline 5th Year*All Passing & $\begin{array}{l}424.36 \\
(10.45)\end{array}$ & $\begin{array}{l}429.58 \\
(10.59)\end{array}$ & $\begin{array}{c}395.21 \\
(9.73)\end{array}$ & $\begin{array}{c}397.90 \\
(9.79)\end{array}$ & $\begin{array}{c}394.69 \\
(9.72)\end{array}$ & $\begin{array}{c}395.48 \\
(9.74)\end{array}$ \\
\hline Before*All Passing Group & $\begin{array}{l}-70.54 \\
(1.48)\end{array}$ & $\begin{array}{l}-66.71 \\
(1.40)\end{array}$ & $\begin{array}{l}-17.86 \\
(0.40)\end{array}$ & $\begin{array}{c}0.61 \\
(0.02)\end{array}$ & $\begin{array}{l}35.62 \\
(1.11)\end{array}$ & $\begin{array}{l}20.03 \\
(0.62)\end{array}$ \\
\hline Before*2nd Year*All Passing & $\begin{array}{l}-41.59 \\
(1.31)\end{array}$ & $\begin{array}{l}-45.14 \\
(1.42)\end{array}$ & $\begin{array}{r}-47.50 \\
(1.49)\end{array}$ & $\begin{array}{l}-47.29 \\
(1.49)\end{array}$ & $\begin{array}{l}-47.50 \\
(1.49)\end{array}$ & $\begin{array}{l}-47.44 \\
(1.49)\end{array}$ \\
\hline Before ${ }^{\star}$ rd Year*All Passing & $\begin{array}{l}-63.05 \\
(1.45)\end{array}$ & $\begin{array}{l}-65.99 \\
(1.52)\end{array}$ & $\begin{array}{l}-70.71 \\
(1.63)\end{array}$ & $\begin{array}{l}-70.43 \\
(1.62)\end{array}$ & $\begin{array}{l}-70.83 \\
(1.63)\end{array}$ & $\begin{array}{l}-70.73 \\
(1.63)\end{array}$ \\
\hline Before ${ }^{\star} 4$ th Year*All Passing & $\begin{array}{l}-73.98 \\
(1.45)\end{array}$ & $\begin{array}{l}-77.71 \\
(1.52)\end{array}$ & $\begin{array}{l}-84.71 \\
(1.66)\end{array}$ & $\begin{array}{l}-83.94 \\
(1.65)\end{array}$ & $\begin{array}{l}-84.67 \\
(1.66)\end{array}$ & $\begin{array}{l}-84.46 \\
(1.66)\end{array}$ \\
\hline Before ${ }^{\star} 5$ th Year*All Passing & $\begin{array}{l}27.25 \\
(0.47)\end{array}$ & $\begin{array}{l}22.16 \\
(0.38)\end{array}$ & $\begin{array}{l}12.70 \\
(0.22)\end{array}$ & $\begin{array}{l}13.50 \\
(0.23)\end{array}$ & $\begin{array}{l}12.59 \\
(0.22)\end{array}$ & $\begin{array}{l}12.87 \\
(0.22)\end{array}$ \\
\hline Other Control variables: & & & & & & \\
\hline Highest Grade Attained & & & $\begin{array}{l}138.25 \\
(17.52)\end{array}$ & $\begin{array}{c}92.53 \\
(13.15)\end{array}$ & $\begin{array}{c}87.36 \\
(14.04)\end{array}$ & $\begin{array}{c}72.61 \\
(11.79)\end{array}$ \\
\hline Age & & & $\begin{array}{l}286.31 \\
(13.68)\end{array}$ & $\begin{array}{c}172.31 \\
(8.57)\end{array}$ & $\begin{array}{l}202.75 \\
(10.42)\end{array}$ & $\begin{array}{l}184.51 \\
(9.53)\end{array}$ \\
\hline Age Squared/100 & & & $\begin{array}{c}-344.47 \\
(9.85)\end{array}$ & $\begin{array}{c}-316.74 \\
(9.39)\end{array}$ & $\begin{array}{c}-349.16 \\
(10.63)\end{array}$ & $\begin{array}{r}-340.71 \\
(10.39)\end{array}$ \\
\hline Age when Took the GED & & & $\begin{array}{c}184.40 \\
(6.72)\end{array}$ & $\begin{array}{r}-418.63 \\
(16.10)\end{array}$ & $\begin{array}{c}-215.14 \\
(9.10)\end{array}$ & $\begin{array}{r}-296.67 \\
(12.50)\end{array}$ \\
\hline Age when Took the GED^2/100 & & & $\begin{array}{c}-317.65 \\
(6.11)\end{array}$ & $\begin{array}{l}791.43 \\
(16.24)\end{array}$ & $\begin{array}{c}357.31 \\
(8.15)\end{array}$ & $\begin{array}{l}524.23 \\
(11.78)\end{array}$ \\
\hline Hispanic & & & $\begin{array}{l}-19.48 \\
(0.79)\end{array}$ & $\begin{array}{l}20.12 \\
(0.91)\end{array}$ & $\begin{array}{l}68.29 \\
(3.46)\end{array}$ & $\begin{array}{l}92.80 \\
(4.73)\end{array}$ \\
\hline African- American & & & $\begin{array}{c}-1260.74 \\
(43.06)\end{array}$ & $\begin{array}{r}-735.67 \\
(28.34)\end{array}$ & $\begin{array}{c}-572.18 \\
(23.41)\end{array}$ & $\begin{array}{r}-505.09 \\
(21.19)\end{array}$ \\
\hline Asian & & & $\begin{array}{c}-316.55 \\
(3.05)\end{array}$ & $\begin{array}{c}249.57 \\
(2.57)\end{array}$ & $\begin{array}{l}41.02 \\
(0.46)\end{array}$ & $\begin{array}{c}152.99 \\
(1.70)\end{array}$ \\
\hline Other Ethnicity & & & $\begin{array}{c}-393.16 \\
(7.12)\end{array}$ & $\begin{array}{c}-153.53 \\
(3.05)\end{array}$ & $\begin{array}{c}-116.37 \\
(2.56)\end{array}$ & $\begin{array}{l}-73.32 \\
(1.62)\end{array}$ \\
\hline Took GED in Spanish & & & $\begin{array}{c}-397.40 \\
(6.14)\end{array}$ & $\begin{array}{l}86.45 \\
(1.50)\end{array}$ & $\begin{array}{l}-50.60 \\
(1.00)\end{array}$ & $\begin{array}{l}61.66 \\
(1.21)\end{array}$ \\
\hline Time Fixed Effect Included & No & Yes & Yes & Yes & Yes & Yes \\
\hline Pre-Test Taking Experience & No & No & No & Yes & No & Yes \\
\hline Pre-Test Taking Earnings & No & No & No & No & Yes & Yes \\
\hline $\begin{array}{l}\text { Number of Observations } \\
\text { Number of Individuals }\end{array}$ & \multicolumn{6}{|c|}{$1,044,604$} \\
\hline R-squared & 0.018 & 0.019 & 0.080 & 0.192 & 0.273 & 0.277 \\
\hline
\end{tabular}

Note: t-values based on robust standard errors are shown in parentheses. Furthermore, the standard errors are obtained assuming disturbances are independent across individuals but allows for dependence for individuals' repeated observations over time, i.e. within group/individual correlation of disturbance term. 
Table 6.

Estimated Quarterly Earnings Differences, GED Holders and Non-GED Holders, based on Results in Table 5.

\begin{tabular}{|c|c|c|c|c|c|c|}
\hline Year Since Attempted GED & Model 1 & Model 2 & Model 3 & Model 4 & Model 5 & Model 6 \\
\hline & \multicolumn{6}{|c|}{ Comparison Group: All Fail } \\
\hline First Year & $\begin{array}{r}-334.41 \\
(75.99)\end{array}$ & $\begin{array}{c}-330.43 \\
(76.02)\end{array}$ & $\begin{array}{c}-259.08 \\
(71.06)\end{array}$ & $\begin{array}{c}-182.20 \\
(61.07)\end{array}$ & $\begin{array}{c}-149.65 \\
(53.32)\end{array}$ & $\begin{array}{c}-152.16 \\
(52.95)\end{array}$ \\
\hline Second Year & $\begin{array}{c}-160.36 \\
(84.54)\end{array}$ & $\begin{array}{c}-161.85 \\
(84.55)\end{array}$ & $\begin{array}{l}-95.58 \\
(79.84)\end{array}$ & $\begin{array}{l}-18.42 \\
(71.28)\end{array}$ & $\begin{array}{c}13.48 \\
(65.75)\end{array}$ & $\begin{array}{c}11.12 \\
(65.30)\end{array}$ \\
\hline Third Year & $\begin{array}{c}-174.48 \\
(95.03)\end{array}$ & $\begin{array}{c}-177.39 \\
(95.04)\end{array}$ & $\begin{array}{c}-115.93 \\
(90.92)\end{array}$ & $\begin{array}{l}-39.12 \\
(82.17)\end{array}$ & $\begin{array}{c}-7.65 \\
(77.70)\end{array}$ & $\begin{array}{c}-9.95 \\
(77.12)\end{array}$ \\
\hline Fourth Year & $\begin{array}{l}-229.03 \\
(104.41)\end{array}$ & $\begin{array}{c}-229.39 \\
(104.42)\end{array}$ & $\begin{array}{l}-173.27 \\
(100.47)\end{array}$ & $\begin{array}{l}-95.25 \\
(92.17)\end{array}$ & $\begin{array}{l}-64.43 \\
(88.31)\end{array}$ & $\begin{array}{l}-66.50 \\
(87.72)\end{array}$ \\
\hline Fifth Year & $\begin{array}{c}-172.79 \\
(110.80)\end{array}$ & $\begin{array}{c}-176.48 \\
(110.77)\end{array}$ & $\begin{array}{c}-125.72 \\
(107.16)\end{array}$ & $\begin{array}{l}-47.36 \\
(99.64)\end{array}$ & $\begin{array}{l}-16.84 \\
(96.06)\end{array}$ & $\begin{array}{l}-18.79 \\
(95.48)\end{array}$ \\
\hline \multicolumn{7}{|l|}{ Test $\mathrm{H}_{0}:$ GED Effect $=0$ (P-values) } \\
\hline First Year & $<0.001$ & $<0.001$ & $<0.001$ & 0.003 & 0.005 & 0.004 \\
\hline Second Year & 0.058 & 0.056 & 0.231 & 0.796 & 0.838 & 0.865 \\
\hline Third Year & 0.066 & 0.062 & 0.202 & 0.634 & 0.922 & 0.897 \\
\hline Fourth Year & 0.028 & 0.028 & 0.085 & 0.301 & 0.466 & 0.448 \\
\hline Fifth Year & 0.119 & 0.111 & 0.241 & 0.635 & 0.861 & 0.844 \\
\hline & \multicolumn{6}{|c|}{ Comparison Group: All Pass } \\
\hline First Year & $\begin{array}{r}-263.87 \\
(68.88)\end{array}$ & $\begin{array}{c}-263.73 \\
(68.93)\end{array}$ & $\begin{array}{c}-241.22 \\
(64.46)\end{array}$ & $\begin{array}{r}-182.81 \\
(56.00)\end{array}$ & $\begin{array}{c}-185.28 \\
(49.30)\end{array}$ & $\begin{array}{r}-172.19 \\
(48.92)\end{array}$ \\
\hline Second Year & $\begin{array}{l}-48.24 \\
(77.17)\end{array}$ & $\begin{array}{l}-50.01 \\
(77.18)\end{array}$ & $\begin{array}{l}-30.22 \\
(72.81)\end{array}$ & $\begin{array}{c}28.26 \\
(65.68)\end{array}$ & $\begin{array}{l}25.35 \\
(60.96)\end{array}$ & $\begin{array}{c}38.53 \\
(60.51)\end{array}$ \\
\hline Third Year & $\begin{array}{l}-40.90 \\
(87.33)\end{array}$ & $\begin{array}{l}-44.69 \\
(87.36)\end{array}$ & $\begin{array}{l}-27.37 \\
(83.58)\end{array}$ & $\begin{array}{c}30.70 \\
(76.09)\end{array}$ & $\begin{array}{c}27.55 \\
(72.19)\end{array}$ & $\begin{array}{c}40.76 \\
(71.64)\end{array}$ \\
\hline Fourth Year & $\begin{array}{l}-84.51 \\
(96.66)\end{array}$ & $\begin{array}{l}-84.97 \\
(96.67)\end{array}$ & $\begin{array}{l}-70.70 \\
(93.06)\end{array}$ & $\begin{array}{l}-11.92 \\
(86.01)\end{array}$ & $\begin{array}{l}-15.38 \\
(82.69)\end{array}$ & $\begin{array}{c}-2.07 \\
(82.13)\end{array}$ \\
\hline Fifth Year & $\begin{array}{l}-129.51 \\
(102.57)\end{array}$ & $\begin{array}{l}-131.93 \\
(102.54)\end{array}$ & $\begin{array}{r}-120.57 \\
(99.31)\end{array}$ & $\begin{array}{l}-61.46 \\
(93.04)\end{array}$ & $\begin{array}{l}-65.05 \\
(89.86)\end{array}$ & $\begin{array}{l}-51.68 \\
(89.32)\end{array}$ \\
\hline \multicolumn{7}{|l|}{ Test $\mathrm{H}_{0}$ :GED Effect $=0$ (P-values) } \\
\hline First Year & $<0.001$ & $<0.001$ & $<0.001$ & 0.001 & $<0.001$ & $<0.001$ \\
\hline Second Year & 0.532 & 0.517 & 0.678 & 0.667 & 0.678 & 0.524 \\
\hline Third Year & 0.640 & 0.609 & 0.743 & 0.687 & 0.703 & 0.569 \\
\hline Fourth Year & 0.382 & 0.379 & 0.447 & 0.890 & 0.852 & 0.980 \\
\hline Fifth Year & 0.207 & 0.198 & 0.225 & 0.509 & 0.469 & 0.563 \\
\hline \multicolumn{7}{|l|}{ Included Controls } \\
\hline Time Fixed Effect & No & Yes & Yes & Yes & Yes & Yes \\
\hline Age, Schooling, Ethnicity & No & No & Yes & Yes & Yes & Yes \\
\hline Pre-Test Taking Experience & No & No & No & Yes & No & Yes \\
\hline Pre-Test Taking Earnings & No & No & No & No & Yes & Yes \\
\hline $\begin{array}{l}\text { Number of Observations } \\
\text { Number of Individuals }\end{array}$ & \multicolumn{6}{|c|}{$1,044,604$} \\
\hline R-squared & 0.018 & 0.019 & 0.080 & 0.192 & 0.273 & 0.277 \\
\hline
\end{tabular}

Note: Standard errors are shown in parentheses. 


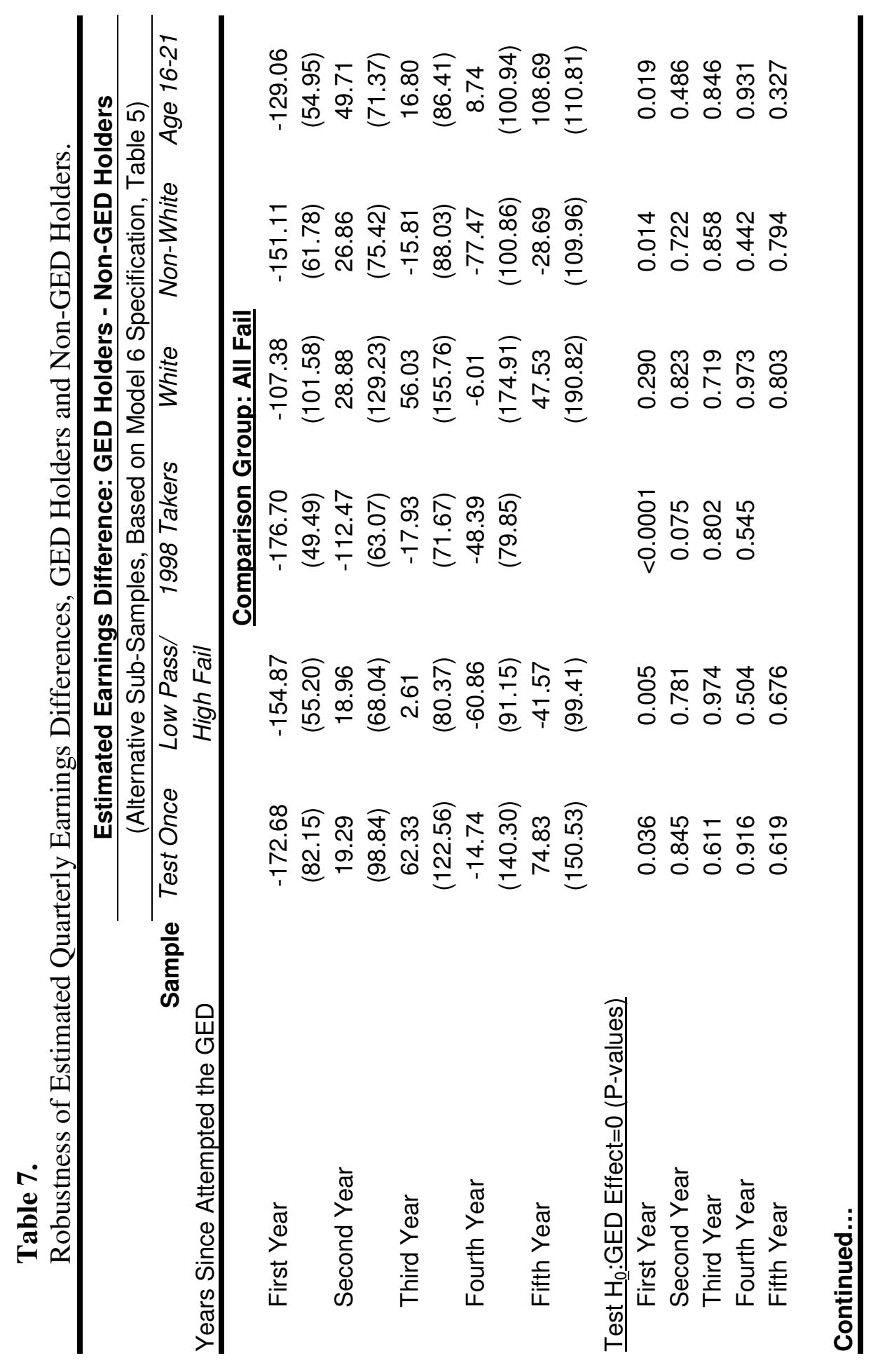




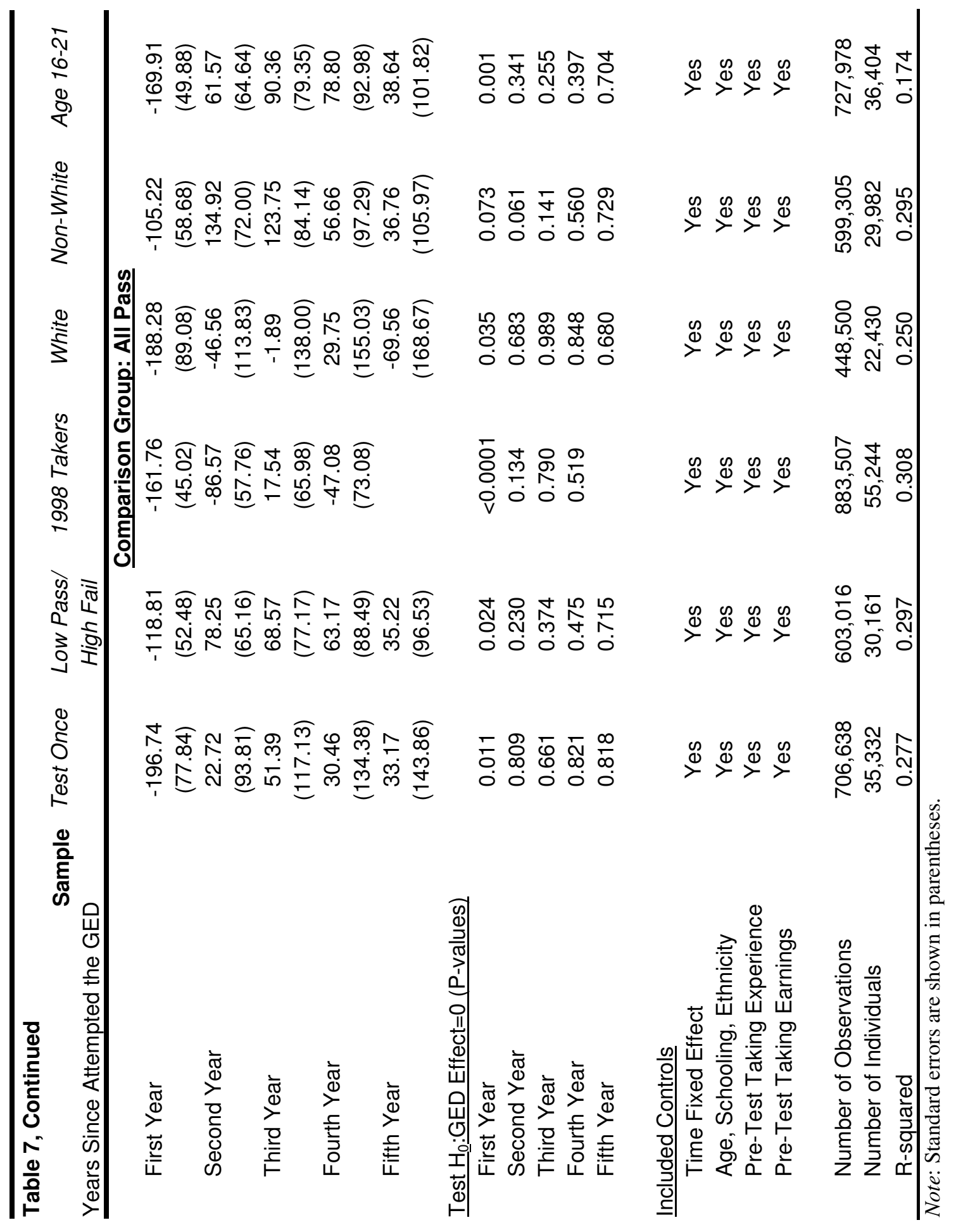




\section{Figure 1.}

Quarterly Earnings by Quarter From Time Attempted the GED - Men, Ages 16-40.

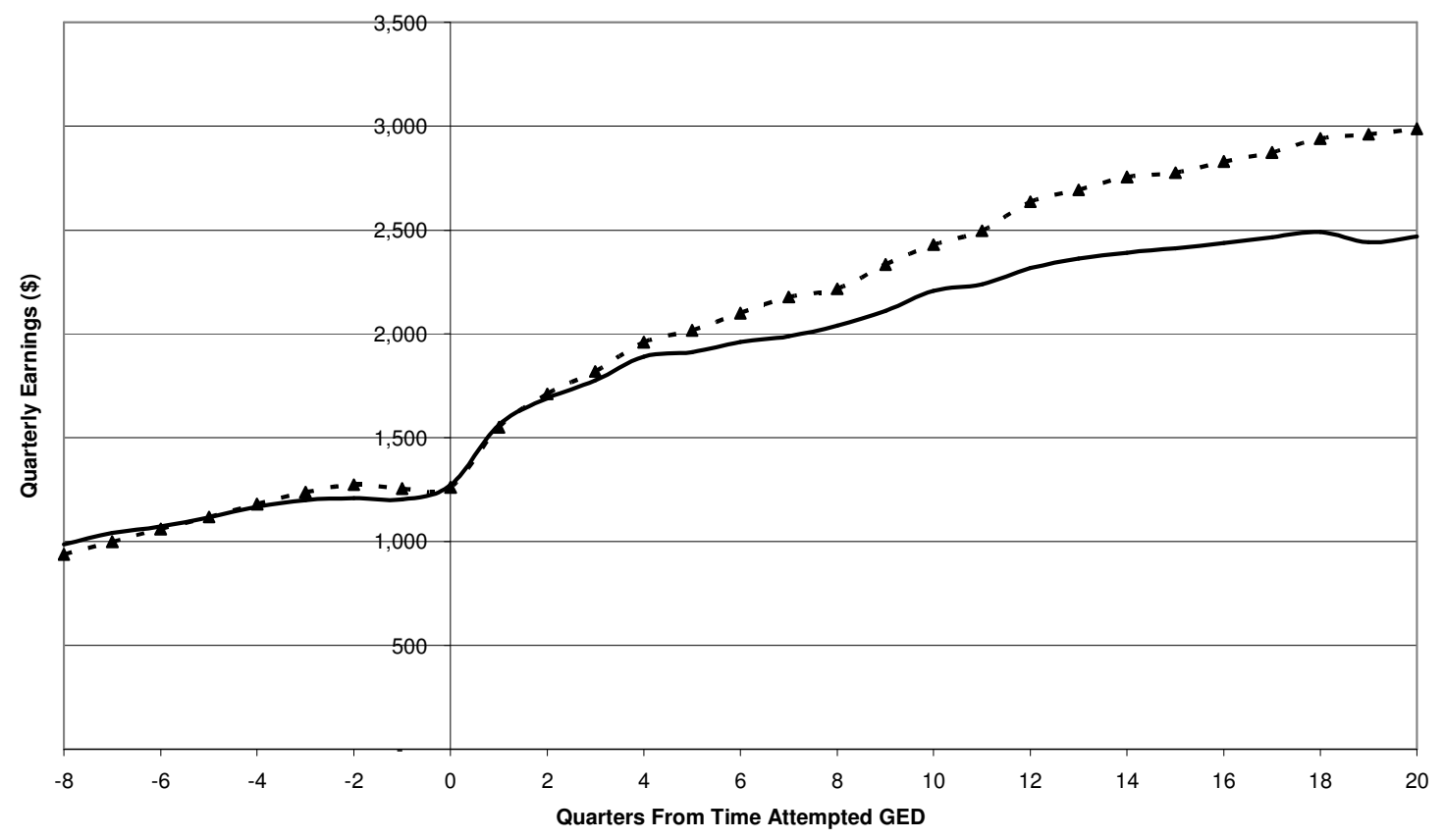

- - Passed GED — Failed - GED

\section{Figure 2.}

Percent with Reported Earnings by Quarter From Time Attempted the GED - Men, Ages 16-40.

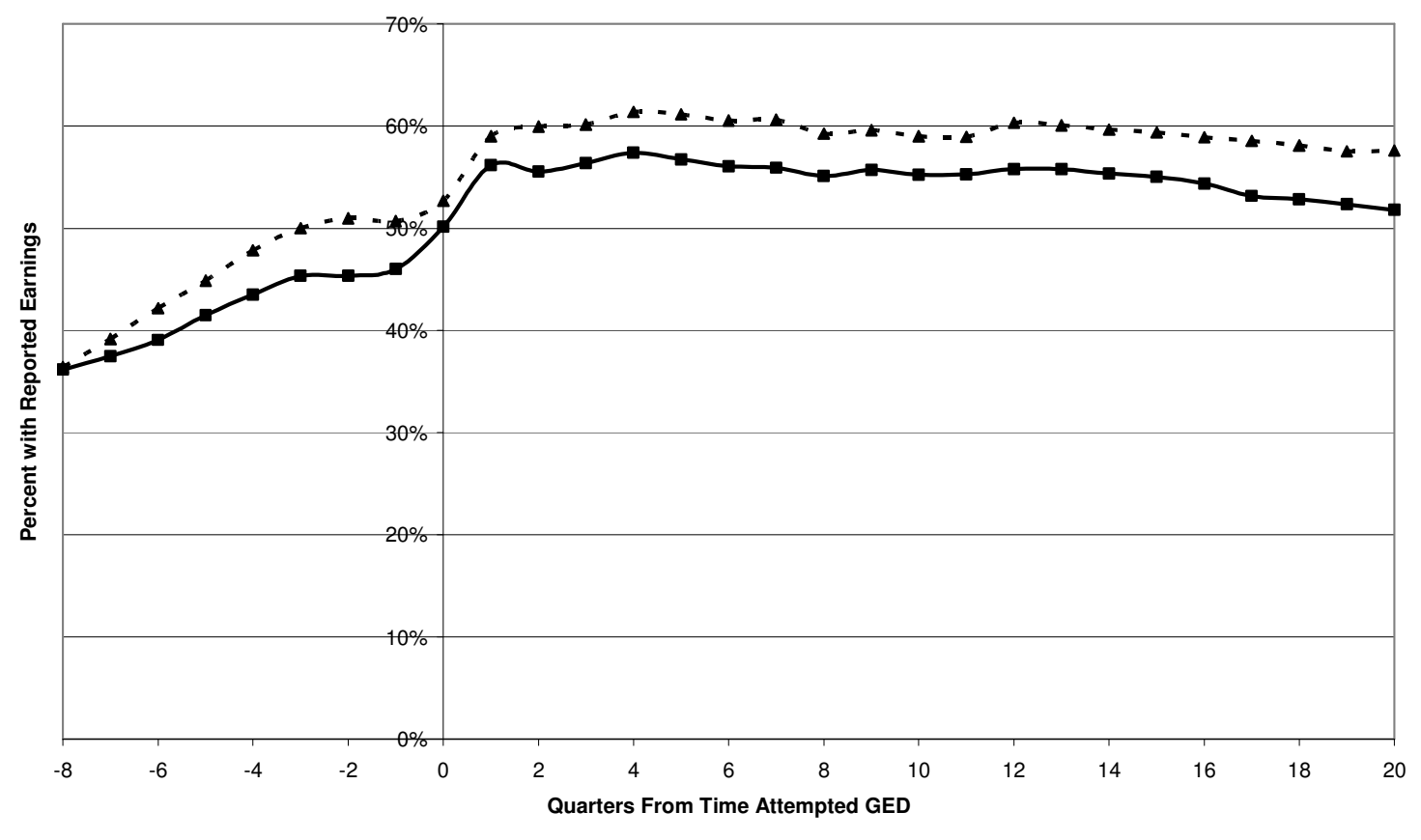

$\because-$ Passed GED $\rightarrow$-Failed - GED 
Figure 3.

Age 16-39 GED Testing Volumes in Texas and Florida for 1989-2001

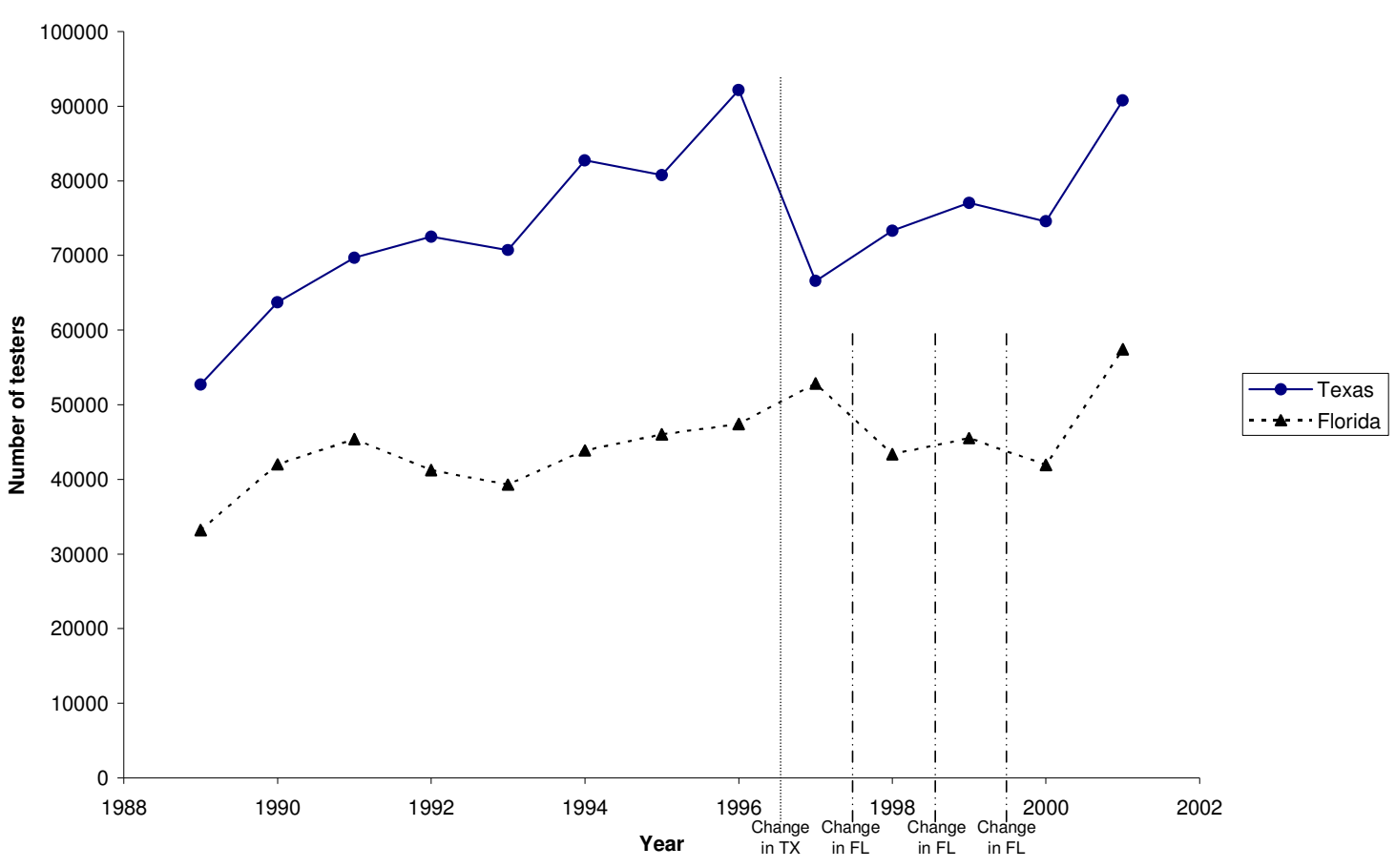

